bioRxiv preprint doi: https://doi.org/10.1101/2021.10.16.464542; this version posted October 16, 2021. The copyright holder for this preprint (which was not certified by peer review) is the author/funder, who has granted bioRxiv a license to display the preprint in perpetuity. It is made available under aCC-BY 4.0 International license.

\title{
1 Oxidative stress induces inflammation of lens cells and triggers immune surveillance of ocular tissues
}

2 Brian Thompson ${ }^{1}$, Emily A. Davidson ${ }^{1,2}$, Ying Chen ${ }^{1}$, David J. Orlicky ${ }^{3}$, David C. Thompson ${ }^{1,4}$, Vasilis Vasiliou ${ }^{1 *}$

3

41 Department of Environmental Health Sciences, Yale School of Public Health, Yale University, 60 College Street, New $5 \quad$ Haven, CT, USA.

2 Department of Cellular \& Molecular Physiology, Yale School of Medicine, Yale University, New Haven, CT, USA.

73 Department of Pathology, Anschutz School of Medicine, University of Colorado, Aurora, CO, USA.

4 Department of Clinical Pharmacy, Skaggs School of Pharmacy and Pharmaceutical Sciences, University of Colorado

9 Denver, Aurora, CO, USA.

10

* Corresponding author vasilis.vasiliou@yale.edu 


\section{Abstract:}

Recent reports have challenged the notion that the lens is immune-privileged. However, these studies have not fully identified the molecular mechanism(s) that promote immune surveillance of the lens. Using a mouse model of targeted glutathione (GSH) deficiency in ocular surface tissues, we have investigated the role of oxidative stress in upregulating cytokine expression and promoting immune surveillance of the eye. RNA-sequencing of lenses from postnatal day (P) 1aged Gclc $c^{f / f} ; L e-C r e^{T g /-}(\mathrm{KO})$ and Gclf ${ }^{f / f} ; L e-C r e^{-/-}$control (CON) mice revealed upregulation of many cytokines (e.g., CCL4, GDF15, CSF1) and immune response genes in the lenses of KO mice. The eyes of KO mice had a greater number of cells in the aqueous and vitreous humors at P1, P2O and P50 than age-matched CON and Gclc ${ }^{w / w} ;$ Le-Cre ${ }^{T g /-}$ (CRE) mice. Histological analyses revealed the presence of innate immune cells (i.e., macrophages, leukocytes) in ocular structures of the KO mice. At P20, the expression of cytokines and ROS content was higher in the lenses of KO mice than in those from age-matched CRE and CON mice, suggesting that oxidative stress may induce cytokine expression. In vitro administration of the oxidant, hydrogen peroxide, and the depletion of GSH (using buthionine sulfoximine (BSO)) in 21EM15 lens epithelial cells induced cytokine expression, an effect that was prevented by co-treatment of the cells with $N$-acetyl-L-cysteine (NAC), a antioxidant. The in vivo and ex vivo induction of cytokine expression by oxidative stress was associated with the expression of markers of epithelial-to-mesenchymal transition (EMT), $\alpha$-SMA, in lens cells. Given that EMT of lens epithelial cells causes posterior capsule opacification (PCO), we propose that oxidative stress induces cytokine expression, EMT and the development of PCO in a positive feedback loop. Collectively these data indicate that oxidative stress induces inflammation of lens cells which promotes immune surveillance of ocular structures.

Keywords: Microphthalmia, Inflammation, Ocular Immune System, Glutathione, Lens, Oxidative Stress

Highlights:

- Immune surveillance of ocular structures occurs in mouse eyes deficient in glutathione.

- Oxidative stress upregulates the expression of pro-inflammatory cytokines (e.g., GDF15, CSF1) in lens cells in vitro and in vivo.

- The upregulation of cytokines in lens cells is associated with markers of an epithelial-to-mesenchymal transition phenotype.

- Oxidative stress-induced inflammation and associated epithelial-to-mesenchymal transition may play a role in the development of posterior capsule opacification. 
60

The lens, an avascular tissue surrounded by a thick basement membrane, has a unique relationship with the immune system. The lens is connected to the vascular and lymphatic systems throughout early eye development via the hyaloid vasculature, a temporary branch of the ophthalmic artery [1,2]. Shortly after birth, the hyaloid vasculature regresses in a process mediated by macrophages $[3,4]$. Notably, macrophages are also involved in the removal of apoptotic epithelial cells prior to lens cavity closure [5]. Following regression of the hyaloid vasculature and closure of the lens cavity, the lens has been thought to be immune-privileged, i.e., tolerant to the placement of allografts within the eye.

Several recent experimental results have challenged this dogma. First, the deletion of a cell-cell adhesion protein abundant in lens cells, $\mathrm{N}$-cadherin, in the developing lens impairs lens development and induces immune surveillance of the lens and other ocular structures (i.e., cornea, vitreous humor, retina) from as early as embryonic day (E) 18.5 [6]. Second, following cataract surgery in mice, the expression of many cytokines is increased in lens epithelial cells prior to infiltration of immune cells into the remnant lens capsule [7]. Third, the zonule fibers that are connected to the lens provide a conduit for the trafficking of immune cells to the lens $[6,8,9]$. Fourth, damage to the cornea induces surveillance of the lens by immune cells [8]. Lastly, the chicken, mouse and human lens epithelium contain resident immune cells [9]. Despite this mounting evidence, the molecular mechanism(s) responsible for promoting immune surveillance of the lens remain to be elucidated.

Oxidative stress manifests as a result of an imbalance between antioxidants and oxidants (e.g., reactive oxygen species (ROS)) such that oxidants prevail [10]. Oxidative stress stimulates inflammation by activating the NF-KB signaling pathway $[11,12]$ and serving as a secondary messenger for the pro-inflammatory cytokine TNF $\alpha$ [13], thus ROS both stimulates and mediates inflammation. ROS is generated in the lens by a myriad of exogenous (e.g., radiation, pharmaceutical drugs, cigarette smoke) and endogenous (e.g., NADPH oxidases, cellular respiration) sources [14, 15], and may also be generated by infiltrating leukocytes [16]. Oxidative stress contributes to a common complication of cataract surgery, posterior capsule opacification (PCO) [17], which is characterized by the epithelial-to-mesenchymal transition of the lens epithelial cells that remain following cataract surgery [18-20].

In the present study, we describe that oxidative stress can induce an inflammatory response in lens epithelial cells. We report that the lens-specific deletion of Glutamate-Cysteine Ligase Catalytic Subunit (Gclc), a gene that encodes the ratelimiting enzyme in the biosynthesis of GSH, results in oxidative stress and triggers an inflammatory response that is characterized by a significant upregulation in the gene expression of several classes of cytokines in lens cells. We then replicated the system in vitro with cultured lens epithelial cells by treatment with buthionine sulfoximine (BSO), an irreversible glutamate cysteine ligase inhibitor, or hydrogen peroxide $\left(\mathrm{H}_{2} \mathrm{O}_{2}\right)$ and found that this induces cytokine expression. Interestingly, treatment with BSO elicited the expression of more cytokines in these cells than did treatment with the oxidant $\mathrm{H}_{2} \mathrm{O}_{2}$, suggesting differential responses induced by these treatments. Lastly, we found that supplementation of lens epithelial explants with an antioxidant, $\mathrm{N}$-acetyl-L-cysteine, reduced the expression of cytokines and prevented the induction of markers of EMT. Collectively, these results suggest that inflammation and PCO may both 
be prevented by post-cataract treatments that include an antioxidant or the upregulation of the endogenous antioxidant systems.

\section{Methods}

\section{Mouse Lines}

The creation of Gclc control (CON), Gclc knockout (KO) and Le-Cre control (CRE) mice used in this study have been previously described [21]. Briefly, Gclc homozygous floxed mice [22] and Le-Cre hemizygous mice [23] were crossed to delete Gclc from the cellular precursors of the eyelid, epithelium of the cornea, conjunctiva and lens from as early as embryonic day (E) 9. Mice of the three genotypes were maintained on a C57BL/6 and FVB/N mixed background. They were group-housed (no more than 5 mice per cage) and maintained on a 12-hour light-dark cycle, with food and water available ad libitum. All experiments were performed in strict accordance with the National Institutes of Health guidelines, and protocols were approved by the Yale University Institutional Animal Care and Use Committee.

\section{RNA sequencing (RNA-seq) Library Preparation and Sequencing}

The RNA-seq data used in this study have been previously published [21]. Briefly, the lenses of mice aged postnatal day (P) 1 were collected from KO and CON mice (which were anesthetized by the isoflurane open drop method and euthanized by cervical dislocation) and stored in $200 \mu \mathrm{L}$ RNAlater solution (Invitrogen, Waltham, MA) at $-80^{\circ} \mathrm{C}$ until extraction. The lenses from three mice (i.e., six lenses) were pooled into a biological replicate and three biological replicates were used per genotype (i.e., 9 mice total per genotype). Total RNA was isolated from the biological replicates using the RNeasy Micro Kit (QIAGEN, Venlo, Netherlands) per the manufacturer's instructions, and the RNA integrity number (RIN) was determined using the Agilent 2100 Bioanalyzer RNA 6000 Pico assay. cDNA libraries were prepared from total RNA samples with an RIN $\geq 8.0$ using the NEBNext ${ }^{\circ}$ Single Cell/Low Input RNA Library Prep Kit for Illumina (New England BioLabs). An Illumina NovaSeq 6000 machine with an S4 flow cell was used to generate pairwise 100 bp reads (performed by the Yale Center for Genome Analysis).

\section{RNA-seq Analysis and Bioinformatics}

The analysis of the RNA-seq data has been previously described in detail [21] and can be accessed at NCBI Gene Expression Omnibus (GEO) (accession number GSE175394). Briefly, all data analyses were performed using the Galaxy web platform [24] [accessed at usegalaxy.org], with default settings used for all tools (unless otherwise stated). Read sequence qualities were determined using the FastQC tool (v0.72+galaxy1), with low quality reads being trimmed using a sliding window (phred $\geq 20$ ), and ambiguous bases $(N)$ and any contaminating sequencing adapters removed using the Trimmomatic tool 
[25]. HISAT2 (v2.1.0+galaxy5)[26] was used to map the trimmed reads to the Mus musculus reference genome (GRCm38/mm10). featureCounts (v1.6.4+galaxy1) [27] was used to count mapped reads. DESeq2 (v2.11.0.6) [28] was used for differential expression analyses. Differentially-expressed genes (DEGs) were identified through satisfaction of the following criteria: $\geq \pm 1.0 \log _{2}$ fold change (log2FC) and adjusted $P$ value $<0.05$ (Benjamini-Hochberg method[29]).

The Database for Annotation, Visualization and Integrated Discovery (DAVID) bioinformatics resource [30] was used to perform gene ontology (GO) functional annotation analysis on identified DEGs. Ingenuity Pathway Analysis (IPA) (Version 52912811, Ingenuity Systems, QIAGEN) was used to identify 'canonical pathways' in the upregulated DEGs. The cytokinecytokine receptor interaction pathway map was generated using the KEGG Mapper program (31423653).

\section{Histological Analysis of Mouse Eyes}

P1-aged mice were euthanized by swift decapitation and a piece of the tail was removed for genotyping by PCR, as previously described [22]. Mice aged P20 and P50 were anesthetized by the isoflurane open drop method, euthanized by cervical dislocation. The eyes were then rapidly enucleated and any contaminating tissues were removed. The mouse heads or eyes were fixed in Davidson's Solution for 24 hours at $4^{\circ} \mathrm{C}$ and subsequently stored in $70 \%$ EtOH. Yale Pathology Tissue Services (YPTS) processed the tissues for histological analysis, i.e., conducted paraffin embedding, sectioning (5 $\mu \mathrm{m}$ thickness) and mounting onto glass slides. YPTS then either stained the resultant slides with hematoxylin and eosin (H\&E) or subjected them to immunohistochemical analysis (per their standard protocols). At least two H\&E-stained sections from the eyes of three CON, CRE or KO mice (aged P1, P20 or P50) were imaged with a Nikon Eclipse E200 microscope with an Axiocam 503 camera (Zeiss) attached and the number of cells within the aqueous and vitreous humors were counted using the NIH Image J software [31]. Cell counts are presented as means and associated standard deviation.

\section{Cell Culture}

The mouse lens epithelial cell line, 21EM15, was obtained from Dr. Salil Lachke (Department of Biological Sciences, University of Delaware). Cells were cultured in Dulbecco's Modified Eagle Medium (DMEM) (Thermo Fisher Scientific Inc., MA) supplemented with $10 \%$ fetal bovine serum (Sigma-Aldrich, MO), $1 \%$ antibiotic-antimycotic (Sigma-Aldrich, St. Louis, $\mathrm{MO}$ ) and 1\% MEM non-essential amino acids (Sigma-Aldrich, MO) in $60 \mathrm{~mm}$ dishes (Corning, NY) in a humidified atmosphere of $5 \% \mathrm{CO}_{2}$ in air at $37^{\circ} \mathrm{C}$. Cells were treated with $500 \mu \mathrm{M}$ BSO (Sigma-Aldrich, MO) for 48 hours or with $25 \mu \mathrm{M}$ hydrogen peroxide (Cole Palmer, IL) for 24 hours to induce oxidative stress [32, 33]. In other experiments, cells were concomitantly treated with $10 \mathrm{mM} \mathrm{N}$-acetyl-L-cysteine (Sigma-Aldrich, MO ) and $500 \mu \mathrm{M}$ BSO for 48 hours. At the end of the treatment period, cells were rinsed once with phosphate buffered saline (PBS, Gibco, $M A$ ) and removed from the culture dish by a 3-minute treatment with $0.05 \%$ trypsin (Gibco, MA) and the trypsin neutralized with equal parts cell culture medium. The disassociated cells were transferred to a $1.5 \mathrm{~mL}$ microcentrifuge tube (Eppendorf, Hamburg, Germany) and a cell pellet was generated by centrifugation at $500 \mathrm{~g}$ for $3 \mathrm{~min}$ at room temperature. The cell culture media was aspirated from the cell pellet and the pellet was washed twice with room temperature PBS by gently resuspending 
the cell pellet in PBS, centrifugation at $500 \mathrm{~g}$ for $3 \mathrm{~min}$ at room temperature, and aspiration of the PBS. After the final wash, the cell pellet was stored in $100 \mu \mathrm{L}$ of PBS at $-80^{\circ} \mathrm{C}$ for latter analysis.

\section{Lens Epithelial Explant Establishment}

Gclcw/w mice aged P20 were used for the establishment of lens epithelial explants, as previously described [34, 35]. Briefly, mice were anesthetized, euthanized and their eyes enucleated as described in the histological analysis section (above). The lenses were removed and placed into a $35 \mathrm{~mm}$ culture dish (Corning, NY) containing pre-warmed $\left(37^{\circ} \mathrm{C}\right.$ ) Medium 199 supplemented with $0.1 \%$ fetal bovine serum (Sigma-Aldrich, MO), $1 \%$ antibiotic-antimycotic (Sigma-Aldrich, St. Louis, MO) or Medium 199 supplemented with 0.1\% fetal bovine serum (Sigma-Aldrich, MO), 1\% antibiotic-antimycotic (SigmaAldrich, St. Louis, MO), and $10 \mathrm{mM} \mathrm{NAC} \mathrm{(Thermo} \mathrm{Fisher} \mathrm{Scientific).} \mathrm{A} \mathrm{hole} \mathrm{was} \mathrm{made} \mathrm{at} \mathrm{the} \mathrm{posterior} \mathrm{pole,} \mathrm{the} \mathrm{lens} \mathrm{capsule}$ opened, and the fiber cells gently removed. The lens capsule was pinned to the bottom of the culture dish such that the adherent epithelial cells were exposed to the medium. Explants were then individually cultured in a humidified atmosphere of $5 \% \mathrm{CO}_{2}$ at $37^{\circ} \mathrm{C}$ for 24 hours. Six explants were pooled to make one sample and 3 pooled samples were used for each experimental condition (hence a total of 18 mice were used per condition).

\section{RNA Isolation and RT-qPCR}

RNA isolation from mouse lenses

Three CON, CRE and KO mice aged P20 were anesthetized by the isoflurane open drop method, euthanized by cervical dislocation and lenses dissected. Dissected lenses were immediately placed in $100 \mu \mathrm{L}$ RNAlater solution (Thermo Fisher Scientific), flash frozen in liquid nitrogen and stored at $-80^{\circ} \mathrm{C}$ until processing. Total RNA was isolated from the mouse lenses using the RNeasy Plus Micro Kit (QIAGEN, Venlo, Netherlands) per the manufacturer's instructions. Briefly, the lenses were removed from the RNAlater solution, placed in $350 \mu \mathrm{L}$ RLT Plus buffer (QIAGEN, Venlo, Netherlands), and total RNA was isolated per the manufacturer's instructions.

RNA isolation from $21 E M 15$ cells

Total RNA was isolated from the 21EM15 cells using the RNeasy Plus Mini Kit (QIAGEN, Venlo, Netherlands) per the manufacturer's instructions. Each harvested cell pellet was resuspended in $600 \mu \mathrm{L}$ RLT Plus Buffer and were lysed with a Tissuelyser (QIAGEN, Venlo, Netherlands) at a frequency of $30 \mathrm{~Hz}$ for 2 min at $4^{\circ} \mathrm{C}$. Total RNA was isolated per the manufacturers instructions.

RNA isolation from lens epithelial explants

Lens epithelial explants ( 6 explants per experiment per condition) from three independent experiments (i.e., 18 explants total per experimental condition) were placed in were placed in $100 \mu \mathrm{L}$ RNAlater solution, flash frozen in liquid nitrogen 
and stored at $-80^{\circ} \mathrm{C}$ until processing. Total RNA was isolated from these explants using the RNeasy Plus Micro Kit (QIAGEN, Venlo, Netherlands) per the manufacturer's instructions.

\section{$R T-q P C R$}

Each total RNA sample was quantified and analyzed for purity using a spectrophotometer (Nanodrop ND-1000). Five hundred ng of total RNA (from 21EM15 cells or mouse lenses) or $10 \mathrm{ng}$ of total RNA (from explants) were reverse transcribed using the iScript cDNa Synthesis Kit (Bio-Rad, CA) per the manufacturer's instructions. One ng of cDNA from the explants was then pre-amplified using the Quantabio PerfeCTa PreAmp Supermix (Quantabio, MA) with the same primers as used for qPCR (per the manufacturer's instructions) and diluted 20 -fold. Ten ng of cDNA from the 21 EM15 cells, $1 \mathrm{uL}$ of preamplified cDNA from the explants or $75 \mathrm{ng}$ of cDNA from the lenses was then used to estimate the abundance of specific mRNA transcripts using the iTaq Universal SYBR Green Supermix (Bio-Rad, CA) on a CFX96 Real-Time PCR System (Bio-Rad, CA). Relative mRNA transcript abundance was estimated using the $\Delta \mathrm{Ct}$ method [36] with the housekeeping gene, GAPDH, used as an internal normalization control for each sample. Primer sequences used are provided in Supplemental Table 1.

\section{Analysis of ROS levels}

ROS levels were assayed as previously described [37]. Briefly, three P20-aged CON, CRE and KO mice were anesthetized by the isoflurane open drop method, euthanized by cervical dislocation and lenses dissected. The two freshly isolated lenses from each animal were placed into a single 96-well plate containing $200 \mu \mathrm{L}$ Medium 199 (Sigma-Aldrich) maintained at $4^{\circ} \mathrm{C}$. Dihydrorhodamine $123(\mathrm{DHR})(7.5 \mu \mathrm{M})$ (Invitrogen, MA), a colorless stain that easily passes through membranes and is oxidized by ROS into rhodamine 123, and 1 drop of NucBlue Live Ready Probe (Hoescht 33342, Thermo Fisher Scientific, MA) were added to each well and incubated at $4^{\circ} \mathrm{C}$ for 30 minutes. Stained lenses were washed three times in $4^{\circ} \mathrm{C}$ Medium 199 and then $200 \mu \mathrm{L} 4^{\circ} \mathrm{C}$ PBS (Gibco, MA) was added to each well prior to measuring DHR fluorescence intensity at Ex/Em of 507/529 nm and Hoescht 33342 at Ex/Em of 360/460 nm with a microplate reader (Spectramax M3, Molecular Devices). DHR relative fluorescence units (RFU) was expressed as a ratio of the Hoescht $33342 \mathrm{RFU}$ in the same tissue. 1 EM15 cells were cultured in a $60 \mathrm{~mm}$ culture dishes (Corning, NY) and treated with either $500 \mu \mathrm{M}$ BSO, $25 \mu \mathrm{M}$ $\mathrm{H}_{2} \mathrm{O}_{2}$ or $500 \mu \mathrm{M}$ BSO $+10 \mathrm{mM}$ NAC (for the periods described above). Lens epithelial explants were cultured in normal culture media or media containing $10 \mathrm{mM} \mathrm{NAC}$ for 24 or 48 hours, respectively. At the end of the treatment period, the culture medium was aspirated and replaced by $3 \mathrm{~mL}$ of ice-cold Medium 199. Dihydrorhodamine $123(7.5 \mu \mathrm{M})$ and 5 drops of NucBlue Live Ready Probe (Hoescht 33342, Thermo Fischer Scientific, MA) were added to each dish and allowed to incubate for 30 minutes at $4^{\circ} \mathrm{C}$. Stained cells/explants were then washed three times in $4^{\circ} \mathrm{C}$ Medium 199 and finally $3 \mathrm{~mL}$ of fresh $4^{\circ} \mathrm{C}$ Medium 199 was added to each dish. The cells or explants were then either imaged on a AxioVert.A1 microscope (Zeiss) with an Axiocam 305 camera (Zeiss) and using a Photoflor LM 75 light source (89 North, VT). 
$21 \mathrm{EM} 15$ cells were cultured in $60 \mathrm{~mm}$ cell culture dishes (Corning, NY), treated with $500 \mu \mathrm{M}$ BSO or an equivalent volume of medium (control) for 48 hours, harvested by treatment with $0.05 \%$ trypsin for 3 min and the trypsin was neutralized with equal parts cell culture medium. The dissociated cells were transferred to a $1.5 \mathrm{~mL}$ microcentrifuge tube (Eppendorf, Hamburg, Germany) and subjected to centrifugation at $500 \mathrm{~g}$ for $3 \mathrm{~min}$ at room temperature. The cells were lysed by resuspension of the pellet in $250 \mu \mathrm{L}$ RIPA buffer (1\% Nonidet P40, $0.5 \%$ sodium deoxycholate, $0.1 \%$ SDS in PBS), incubation for 10 mins on ice and passing the suspension 10 times each through 22, 25 and 28 gauge series of needles (in that order) [38]. The protein samples were then subjected to centrifugation at $14,000 \mathrm{rpm}$ for $10 \mathrm{~min}$ at $4^{\circ} \mathrm{C}$ and the supernatant was collected. Protein concentrations in the supernatant were quantified using the Pierce BCA Protein Assay Kit (Thermo Fisher Scientific, MA) according to the manufacturer's instructions. Thirty $\mu \mathrm{g}$ of supernatant protein was resolved on a $4-20 \%$ SDS-PAGE gradient gel (Bio-Rad, CA) and transferred to a $0.2 \mu \mathrm{m}$ nitrocellulose blot (Bio-Rad, CA). Primary antibodies (1:1000) directed against NF-kB P65 (Cell Signaling Technologies, 8242T), P-NF-kB P65 (Cell Signaling Technologies, 3033T), IKK- $\beta$ (Cell Signaling Technologies, 8943S), І ІB $\alpha$ (Cell Signaling Technologies, 4814T), P-ІкB $\alpha$ (Cell Signaling Technologies, 2859T) or GAPDH (Abcam, ab9485) were used for immunoblotting. Horse radish peroxidase-conjugated goat anti-rabbit or goat anti-mouse secondary antibodies (1:5000, Cell Signaling Technologies, 7074P2) were used to visualize immunolabeled proteins. Quantitation of band densities was performed using NIH Image J software [31]. Target protein expression was normalized to the corresponding GAPDH expression or unphosphorylated protein, as appropriate. Data are presented as the mean density (and associated standard deviation) of the normalized protein.

\section{Statistical Analysis}

Differences between gene expression and protein expression were determined using Student's unpaired t-test or oneway ANOVA with post-hoc Dunnett's test correction. Differences between cell counts were determined using one-way ANOVA with post-hoc Dunnett's test correction. Differences in ROS are expressed as fold change (of CON) and significance was determined using a one-way ANOVA with post-hoc Dunnett's test correction. All statistical analyses were conducted using GraphPad Prism version 9.1.1 for PC, GraphPad Software, La Jolla California, USA. P $<0.05$ was considered significant.

\section{Results}

\section{Gclc deletion induces an inflammatory response in the lenses of neonatal KO mice}

We have previously described the Gclc/f; $L$ Le-Cre ${ }^{T g /-}$ knockout (KO) mouse model used in this study [21]. Briefly, Gclc gene was specifically deleted from surface ectoderm-derived tissues (i.e., corneal epithelium, conjunctiva, eyelid, lens) from as early as embryonic day (E) 9 by crossing Gclc/f mice [22] with Le-Cre transgene mice [23]. KO mice have an overt microphthalmia phenotype that is characterized by vacuolation of the lens fiber cells at birth, hypercellularity of the retina, cornea and iris by P20, and severe retinal infolding by P50 (Supp. Fig. 1). Controlling for the Le-Cre transgene [39], revealed 
that the microphthalmia phenotype and morphological changes in the KO mice are distinct from those in Le-Cre transgene hemizygous mice, termed CRE (Supp. Fig. 3).

We have previously described the impaired lens development phenotype of KO mice by conducting RNA-seq analysis on lens tissue from KO and CON mice aged P1 [21]. Fifty-three genes associated with the Gene Ontology (GO) term "immune system process" were upregulated in the lenses of KO mice relative to those in CON mice (Fig. 1A, red dots). Complete analysis of the GO terms overrepresented among the up-regulated genes in the lenses of KO mice revealed many terms associated with the immune system/inflammation (e.g., "immune system process", "inflammatory response", "neutrophil chemotaxis", "chemotaxis", "cell adhesion", "chemokine-mediated signaling pathway", "positive regulation of inflammatory response", "immune response") (Fig. 1B). As a sensitivity analysis, the upregulated genes in KO mice were also analyzed with Ingenuity Pathway Analysis; several canonical pathways associated with the immune system/inflammation were overrepresented among the upregulated genes in KO mice (i.e., "agranulocyte adhesion and diapedesis", "granulocyte adhesion and diapedesis", "hepatic fibrosis/hepatic stellate cell activation", "dendritic cell maturation", "atherosclerosis signaling", "phagosome formation", "neuroinflammation signaling pathway", "TREM1 signaling", "IL-10 signaling") (Fig. 1C). Mapping the upregulated transcripts onto the Kyoto Encyclopedia of Genes and Genomes (KEGG) Cytokine-Cytokine Receptor Interaction pathway revealed 42 of the genes involved in this pathway were upregulated (Fig. 1D, highlighted in red) in the lenses of KO mice belonged to the CC subfamily, CXC subfamily, $\gamma$-chain utilizing, IL4-like, IL6/12-like, IL10/28-like, Interferon family, IL1-like cytokines, TNF family, and TGF- $\beta$ family. Of the 45 differentially expressed genes (DEGs) in the lenses of KO mice (aged P1) that mapped to the Cytokine-Cytokine Receptor Interaction pathway, only three genes (CCl27, Cnftr, 4-1Bbl) were downregulated (Fig. 1D, highlighted in blue). Furthermore, many cytokines were among the top 25 upregulated genes in the lenses of KO mice (i.e., Ccl7, Ccl4, Gdf15, Cxcl16) (Supp. Table. 2).

\section{Innate immune cells infiltrate ocular structures of KO mice}

Morphological analysis of the eyes from KO mice showed an increased presence of cells in the aqueous and vitreous humors at P1 compared with age-matched CON mice (Supp. Figs. 1B, 1H; Supp. Fig. 2). Immunohistochemical staining revealed that the vitreous humor of $\mathrm{KO}$ and CON mice at P1 had cells of leukocytic origin present, as indicated by both CD45- (Fig. 2A-C, J-L, open arrows) and CD11b- (Fig, 2D-F, M-O, arrowheads) staining cells; some CD45-positive cells appeared to cross the lens capsule in the eyes of KO mice (Fig. 2L, open arrows). Immunohistochemical staining for CD68 indicated the presence of macrophages in the vitreous humor of both KO and CON mice at P1 (Fig. 2G-I, P-S, closed arrows), which was expected given the role of macrophages in regression of the hyaloid vasculature $[3,4]$. As anticipated, the lenses from CRE mice aged P1 also had a similar number of cells in the vitreous humor as age-matched CON mice (Supp. Fig. 2). Immunohistochemical staining revealed that some of the cells found in the vitreous humor of CRE mice by H\&E staining (Supp. Fig. 3A $\left(B^{\prime}\right)$ were CD45- (Supp. Fig. 3B ( $A^{\prime}, B^{\prime}$, arrowheads) or CD68- staining (Supp. Fig. 3B (F', closed arrows)). 
Histological analysis of the eyes from CON mice aged P20 revealed that the aqueous and vitreous humors were almost entirely devoid of cells (Supp. Figs. 1C, 1D; Supp. Fig. 2). In contrast, histological analysis of the eyes from KO mice aged P20 revealed an increase in the number of cells in the aqueous and vitreous humor (Supp. Figs. 1I, 1j; Supp. Fig. 2). Eyes from KO mice aged P20 had CD45- (Fig. 3A-C, open arrows) and CD11b- (Fig. 3D-F, arrowheads) staining cells of leukocytic origin and CD68 staining macrophages present in the vitreous humor (Fig. 3G-I, closed arrows). As previously noted [6], lens malformation can induce immune surveillance of many ocular structures, a phenomena that was observed in the eyes of KO mice (Fig. 3). In the eyes of KO mice at P2O, CD11b-staining cells were present in the retina, aqueous humor and corneal epithelium (Fig. 3E, F, arrow heads); CD45-staining cells appeared to be exiting the retina into the vitreous humor (Fig. 3C, open arrows); CD68-staining cells were found in the aqueous humor in the KO mice that had formed an aqueous humor (Fig. 3H, closed arrows). Histological analysis of CRE mice aged P20 revealed the presence of an elevated number of cells in the vitreous humor compared with CON mice (Supp. Fig. 2; Supp. Fig. 3A ( $\left.C^{\prime}, D^{\prime}\right)$ ); KO mice aged P20 had an elevated number of cells in the vitreous humor compared with CRE mice (Supp. Fig. 2; Supp. Fig. 3A $\left.\left(C^{\prime}, D^{\prime}\right)\right)$. Immunohistochemical analysis of these eyes revealed CD45-staining cells in the corneal endothelium (Supp. Fig. 3B ( $D^{\prime}$, closed arrow)) and CD68 staining cells in the vitreous humor (Supp. Fig. 3B $\left(\mathrm{G}^{\prime}, \mathrm{H}^{\prime}\right.$, open arrow)). As expected, the eyes from CON and CRE mice aged P50 were almost completely devoid of cells in the aqueous and vitreous humors (Supp. Fig. 1E, F, closed arrows; Supp. Fig. 2; Supp. Fig. 3A ( $\left.\left.E^{\prime}, F^{\prime}\right)\right)$, whereas the eyes from KO mice aged P50 had a greater number of cells in the aqueous and vitreous humors compared with the eyes of CON mice (Supp. Fig. 1K, M; Supp. Fig. 2).

\section{Gclc deletion induces expression of immune system related genes and causes oxidative stress in the lenses of KO mice}

Given the alterations in immune surveillance in the eyes of KO mice, the expression of cytokine genes in the lenses of CON, KO and CRE mice aged P2O were evaluated (Fig. 4A). Since the expression of some cytokine genes in the lenses of $\mathrm{CON}$ mice were undetectable by RT-qPCR, the gene expression is displayed as $\Delta \mathrm{Ct}$, such that a lower $\Delta \mathrm{Ct}$ corresponds to a greater gene expression. For genes with detectable expression levels in the lenses of CON mice ( $C c l 7, C c / 2, G d f 15)$, only the lenses of KO mice had an increase in gene expression (compared with CON mice) (Fig. 4A). The expression of Ptprc and CxCl16 were both upregulated in the lenses of KO mice compared with CRE mice (Fig. 4A). Levels of ROS were elevated in the lenses of P2O-aged KO mice relative to similarly aged CON and CRE mice (Fig. 4B).

\section{Oxidative stress upregulates cytokine expression in lens epithelial cells}

To further evaluate the influence of oxidative stress on cytokine expression in the lens, 21EM15 mouse lens epithelial cells were depleted of GSH by treatment with buthionine sulfoximine (BSO), a chemical inhibitor of GSH biosynthesis. This intervention induced an oxidative stress response as indicated by the upregulation of the antioxidant response element (ARE) genes [40], Gclc and Hmox1 (Fig. 5A), and a marked increase in ROS formation (Fig. 5D). Since 21EM15 cells do not express all of the cytokines that were differentially expressed in the lenses of KO mice [41] (Fig. 1), the effect of BSOinduced oxidative stress on the expression of cytokines could only be evaluated for a limited number of cytokines. BSO- 
induced oxidative stress upregulated the expression of Cxcl1, Cxcl12, Gdf15, Ccl7, Ccl2, and Csf1 (Fig. 5A). Similarly, treatment of $21 \mathrm{EM} 15$ cells with $25 \mu \mathrm{M}$ hydrogen peroxide $\left(\mathrm{H}_{2} \mathrm{O}_{2}\right)$ for 24 hours induced an oxidative stress response that involved upregulated expression of Gclc and Hmox1 (Fig. 5B) and increased ROS formation (Fig. 5D). The $\mathrm{H}_{2} \mathrm{O}_{2}$ treatment upregulated the expression of the cytokines $\mathrm{Ccl} 2, \mathrm{Ccl} 7$, and $\mathrm{Cxcl} 1$ but failed to induce expression of the cytokines $\mathrm{Cxcl12}$, Csf1 or Gdf15 (Fig. 5B). Co-treatment of 21EM15 cells for 48 hours with BSO and the antioxidant N-acetyl-L-cysteine (NAC) prevented the induction of oxidative stress by BSO as indicated by no induction of the expression of Gclc and $\mathrm{Hmox} 1$ and no increase in ROS formation (Figs. 5C \& D). The NAC co-treatment also prevented induction of the cytokines $\mathrm{Ccl} / 7, \mathrm{Cx} / 12$, Gdf15, Ccl2, Csf1, and Cxcl1 (Fig. 5C). Collectively, these results suggest that oxidative stress is capable of inducing cytokine expression in lens epithelial cells.

Given that oxidative stress in lens epithelial cells can activate NF-KB [11, 42-44], an inducer of cytokine gene expression [45], the activation of NF-KB in cultured lens epithelial cells and in vivo lens was evaluated (Supp. Fig. 4). NF-kB activation can be mediated through several mechanisms: i) phosphorphorlyation of NF-kB (P65 subunit), ii) proteasomal degradation of NF-KB, iii) proteasomal degradation of IKK- $\beta$ and/or iv) phosphorylation of IKB $\alpha$ [45]. The effect of BSO-induced oxidative stress (in 21EM15 cells) on these mechanisms for NF-kB activation were evaluated by Western blot (Supp. Figs. 4A \& B). BSO treatment failed to influence NF-KB activation (Supp. Figs. 4A \& B). Expression of genes induced by activated NF-KB in lens cells [46] (i.e., Birc5, Bcl2, Bcl2/1, Birc2) were also unchanged in cells treated with BSO (Supp. Fig. 4C). NF-KBactivated genes were similarly not induced in the lenses of KO mice aged P1 (Supp. Fig 4D).

\section{Epithelial-mesenchymal transition is associated with the increased cytokine expression}

Oxidative stress and, in particular, low GSH-induced oxidative stress transforms lens epithelial cells to myofibroblasts [17]. This transformation is a feature of epithelial-mesenchymal transition (EMT) [18-20], a process characterized by increased expression of alpha-smooth muscle actin ( $\alpha$-SMA) [19]. Therefore, we investigated if the increases in cytokine gene expression were associated with an EMT phenotype (Fig. 6). $\alpha$-SMA positive cells were found throughout the lens epithelium from the anterior pole to the posterior pole in the lenses of KO mice aged P1 (Fig. 6A ( $\mathrm{B}^{\prime}, \mathrm{C}^{\prime}$, closed arrow)). Analysis of $\alpha$-SMA expression in the lenses of KO mice aged P20 similarly revealed $\alpha$-SMA positive cells throughout the lens epithelium (Fig. 6A (E',F', closed arrow)). Intriguingly, the lens epithelium of CRE mice also possessed $\alpha$-SMA staining cells, although this phenotype was not present in the lenses of all CRE mice (in contrast to KO mice where it was present in all eyes analyzed)) (Supp. Figs. 5 A, B \& F, arrow).

\section{Mitigation of oxidative stress in lens epithelial explants prevents induction of cytokine expression}

Given the links between oxidative stress, cytokine expression and EMT [9, 17, 47-50], we wished to explore if antioxidant administration could prevent the induction of cytokines and an EMT phenotype in a lens cataract surgery model, viz. the lens epithelial explant model. This model is a powerful tool for understanding lens epithelial cell biology and pathology, including posterior capsule opacification (PCO), a common complication of cataract surgery [35]. A recent RNA-seq 
experiment found that lens epithelial explants upregulate the expression of cytokines, antioxidant response element genes and markers of EMT within 24 hours of being established (personal communication with Dr. Michael Robinson, [51]). Thus, we investigated the role of oxidative stress in these processes. Treatment of lens epithelial explants with 10 mM NAC reduced oxidative stress as evidenced by reduced expression of Gclc and Hmox1 (Fig. 6B) and reduced the presence of ROS (Fig. 6C). The treatment of lens epithelial explants with $10 \mathrm{mM}$ NAC only had a non-significant effect on preventing EMT, as evidenced by the trend towards increased expression of the lens identity genes, Cdh1 and Maf, and decreased expression of known markers of EMT, Acta2 (Supp. Fig. 6). The NAC treatment also prevented the induction of Csf1 and Gdf15 (Fig. 6E), but did not prevent the induction of $C c / 2, C c / 7$, or $C x c / 1$ (Supp. Fig. 7).

\section{Discussion}

Mounting evidence challenges the long-held notion that the lens is isolated from the immune system [6-9], which may have important implications for ocular health. The mechanism(s) by which immune surveillance of the lens and other ocular structures can be triggered by damage to the lens remains to be understood. The upregulation of cytokine expression in human lens epithelial (HLE-B3, SRA01/04) cells by $\mathrm{H}_{2} \mathrm{O}_{2}$ [32] and ultraviolet $B$ radiation [52] suggests that oxidative stress may elicit an inflammatory response in the lens. To our knowledge, a detailed characterization of oxidative stress-induced lens inflammation has yet to be performed in vitro or in vivo. In the present study, we have extended our previous unexpected finding that deletion of Gclc from the developing lens (and resulting oxidative stress) upregulates the expression of 42 cytokines and promotes immune surveillance of the cornea, aqueous humor and vitreous humor [21]. In addition, we also report that oxidative stress can induce cytokine expression in cultured lens epithelial cells $(\mathrm{Ccl} 2, \mathrm{Ccl} 7$, Csf1, Cxcl1, Cxcl12, Gdf15) and lens epithelial explants (Csf1, Gdf15). Lastly, our data suggest that the upregulation of cytokines is associated with EMT.

We found that oxidative stress upregulated the expression of 42 cytokines in the neonatal lenses of Gclc KO mice and that immune cells were present in the cornea, retina, aqueous humor and vitreous humor of these mice. Cytokines are small secreted proteins that modulate cell growth and differentiation, and activation and migration of immune cells to areas of tissue damage. Chemokines are a class of cytokine secreted from cells that recruit immune cells to a site of tissue damage [53]. Interestingly, amongst the upregulated genes in the lenses of KO mice were potent chemokines for many leukocytes, e.g., $C c / 6$ [54], $C c / 4$ [55], $C c / 7$ [56], $C c / 2$ [57], $C x c / 12$ [58]. It is reasonable to expect that increased secretion of these cytokines contributed to the observed recruitment of the immune cells to the eyes of KO mice (as detected by immunohistochemical staining for CD45, CD11b and CD68). The induction of these chemokines in lens epithelial cells (21EM15) by oxidative stress strongly suggests that the increased expression of these genes in vivo is largely due to increased expression in lens epithelial cells rather than from infiltrating immune cells. This contention is supported by the finding that many of the genes encoding these chemokines are poised for expression (in a state of "open" chromatin) [59], expressed in lens epithelial cells in vitro [41] and in vivo $[60,61]$, and rapidly upregulated in mouse lens epithelial cells following mock cataract surgery [7]. Collectively, these data are consistent with oxidative stress upregulating cytokine 
bioRxiv preprint doi: https://doi.org/10.1101/2021.10.16.464542; this version posted October 16, 2021. The copyright holder for this preprint (which was not certified by peer review) is the author/funder, who has granted bioRxiv a license to display the preprint in perpetuity. It is made available under aCC-BY 4.0 International license.

expression in lens epithelial cells, leading to enhanced immune surveillance of ocular structures. Thus, mitigation of oxidative stress and/or cytokine expression in lens epithelial cells may dampen immune surveillance of ocular structures.

There are many mechanisms by which oxidative stress can induce cytokine expression in cells, one of which is activation of NF-KB [11, 42-44]. The results derived from lens epithelial (21EM15) cells and lenses from KO mice do not support a mechanistic role of NF-kB activation in our experimental settings. Other mechanisms by which oxidative stress can induce cytokine expression include altered histone code [62-66], damaged mitochondrial DNA [67, 68], upregulated IRF1 expression [69] and activated AP-1 [66, 70], STAT3 [71], NLRP3 [72, 73] and MAPK [32] signaling pathways. Which of these mechanisms mediates the effects in the KO lens remains to be established.

Inflammation manifesting in ocular structures after cataract surgery is thought to result from disruption of the bloodaqueous barrier that is formed by the iris and ciliary, prostaglandin release from the iris and ciliary body, or lens-induced uveitis [74-76]. Our results raise the possibility that oxidative stress-induced inflammation of lens epithelial cells may contribute to the inflammation after cataract surgery. This proposal is supported by the finding that, in humans, markers of oxidative stress (i.e., malondialdehyde) and cytokines are elevated in the aqueous humor after cataract surgery [74]. Given that: i) some researchers consider a common complication of cataract surgery, posterior capsule opacification (PCO), to be a form of postoperative inflammation [77], ii) myofibroblasts produce cytokines [78], iii) chemokine gene expression is higher in fibroblasts than in epithelium [79] and iv) lens epithelial cells undergoing EMT express chemokines [80], we hypothesize that the increased expression of cytokine genes induced by oxidative stress may be related to EMT of lens epithelial cells. This hypothesis is supported by our ex vivo experiments in which the treatment of lens epithelial cell explants with the antioxidant NAC reduced oxidative stress, attenuated the development of EMT markers, and prevented the induction of the chemokines Csf1 and Gdf15. It has been reported that ultraviolet B radiation can induce the expression of Gdf15 in lens epithelial cells [52] and Gdf15 expression promotes EMT in colorectal cancers [47]. Our findings that Gdf15 was among the 25 most upregulated genes in the lenses of KO mice and was associated with the development of markers of EMT led us to speculate that oxidative stress-induced expression of Gdf15 may be involved in EMT of lens epithelial cells during PCO. However, our current data cannot eliminate the possibility that the induction of Csf1 may also be involved in the pathogenesis of PCO and/or fibrosis of the lens, as suggested by a report that found a role for CSF1 in macrophage-induced fibrosis of the lens [81]. Future studies will be needed to discern these possibilities.

A hallmark of EMT in the lens has been the presence of $\alpha$-SMA positive cells, which arise from the lens epithelial cells [82]. However, recent work has demonstrated that $\alpha$-SMA expressing cells in the lens can arise from multiple sources including: i) populations of G8 positive mesenchymal precursor cells that reside within the lens epithelium [83], ii) resident lens immune cells [9,50], and iii) infiltrating immune cells [6] (including macrophages [81]). Given the extensive damage to the lens in KO mice and recruitment of immune cells to the lens, it is likely that the source of $\alpha$-SMA positive cells is not homogenous and may involve some (or all) of the described cellular sources.

Taking into account our data and numerous previous reports $[9,17,47-50]$, we postulate that a positive feedback loop exists wherein increases in oxidative stress and cytokine gene expression are connected in a manner that ultimately results in PCO (Fig. 7). Such a positive feedback loop may have important implications for postoperative cataract surgery care. 
Inflammation following cataract surgery is typically controlled by the combined administration of corticosteroids and nonsteroidal anti-inflammatory drugs [76]. While this treatment strategy is effective at dampening the inflammation, its ability to prevent PCO is equivocal [84-89]. The failure of this treatment strategy to prevent PCO may be due to its inability to mitigate oxidative stress [90-93], which is essential for preventing the development of PCO-relevant physiological and molecular events $[17,32,49,94]$. It is hoped that the results of the present study will motivate the exploration of treatment strategies that include antioxidant agents as a means to further reduce postoperative inflammation and prevent PCO formation. Should such a strategy be effective, it may reduce the immense burden of PCO which can affect upwards of $25 \%$ of adults [95] who undergo cataract surgery.

\section{Acknowledgements}

We would like the thank Mr. Rolando Garcia-Milan for his advice on the RNA-seq analysis, the laboratory of Dr. Mark Petrash for their assistance with the histology and the members of the laboratory of Dr. Michael Robinson for their thoughtful discussions.

\section{Author Contributions}

V.V. conceived of the study. B.T., Y.C., and V.V. designed the experiments. B.T. performed the experiments. B.T., E.A.D., Y.C., D.J.O., D.C.T. and V.V. analyzed data, discussed results, wrote and edited the manuscript.

\section{Funding}

This work was supported, in part, by the National Institutes of Health Grants EY017963, EY022313 and K01AA025093. This work was also made possible by CTSA Grant Number TL1 TR001864 from the National Center for Advancing Translational Science (NCATS), components of the National Institutes of Health (NIH), and NIH roadmap for Medical Research. The contents of this manuscript are solely the responsibility of the authors and do not necessarily represent the official view of NIH.

\section{Competing Interests}

The authors declare that they have no competing or financial interests.

\section{Figures Legends}

Figure 1. Inflammatory response in the lenses of KO mice at postnatal day 1 . RNA-sequencing of postnatal day $(P) 1$ lenses revealed changes in genes in KO mice relative to CO mice. (A) Volcano plot illustrating the 530 downregulated 
$(P<0.05)$ and 1022 upregulated $(P<0.05)$ genes in KO mice (pooled samples from 3 mice). The 53 upregulated DEGs that represent the biological processes GO term "immune system process" (red arrow) are indicated by red dots. The probability (- $\log _{10}($ adjusted $\mathrm{P})$ ) (Y-axis) is Benjamini-Hochberg-corrected. Fold changes (KO vs. CON) are displayed on the X-axis as $\log _{2}$ FC. B) Top biological processes (BP) gene ontology (GO) terms among upregulated genes. The -log10(P-Value) for each term is indicated by a blue bar. The number of DEGs among each term is indicated at the righthand end of each bar. P-values are Benjamini-Hochberg adjusted. (C) Top canonical pathways among upregulated genes as identified with Ingenuity Pathway Analysis. The -log10(P-Value) for each canonical pathway is indicated by a blue bar. P-values are Benjamini-Hochberg adjusted. (D) The Kyoto Encyclopedia of Genes and Genomes (KEGG) Mapper Cytokine-Cytokine Receptor Interaction map annotated to highlight DEGs. Colors: blue shading, downregulated; red shading, upregulated. Darker shading colors indicate greater differential expression.

Figure 2: Immunohistochemical analysis of immune cells in the eyes of KO and CON mice aged postnatal day 1. Eyes from CON (A-I) and KO (J-S) mice aged postnatal day (P) 1 were subjected to immunohistochemical staining and counterstained with hematoxylin. CD45 (A-C, J-L, open arrows) and CD11b (D-F, M-O, arrowheads) staining marks nonmacrophage leukocytes. CD68 staining (G-I, P-S, arrows) marks macrophages. Regions in squares in panels D, E, H, K, N and $\mathrm{R}$ are shown at higher magnification in C, F, I, L, $\mathbf{O}$ and S, respectively. Abbreviations: C, cornea; L, lens; R, retina; V, vitreous humor. Magnification is indicated in the lower right corner of each image.

Figure 3: Immunohistochemical analysis of immune cells in the eyes of KO mice aged postnatal day 21. Eyes from KO mice aged postnatal day (P) 20 were subjected to immunohistochemical staining and counterstained with hematoxylin. CD45- (A-C, open arrows) and CD11b staining (D-F, arrowheads) marks non-macrophage leukocytes. CD68-staining (G-I, arrows) marks macrophages. Abbreviations: A, aqueous humor C, cornea; L, lens; R, retina; V, vitreous humor. Magnification is indicated in the lower right corner of each image.

Figure 4: Cytokine gene expression and ROS levels in the lenses of CON, KO and CRE mice aged postnatal day 20. (A) Lenses from CON, CRE and KO mice aged postnatal (P) 20 were analyzed for induction of genes involved in the inflammatory response by reverse transcriptase (RT) quantitative PCR (qPCR), as calculated by the $\triangle C t$ method. GAPDH was used as an internal normalization control. Gene expression $(\Delta \mathrm{Ct})$ is presented as the mean and associated standard deviation from 3 mice. ${ }^{*} \mathrm{P}<0.05$, one-way ANOVA with post-hoc Dunnett's test, compared to group indicated by horizontal bar. $n . d .=$ not detectable (B) ROS production in the lenses of CON, KO and CRE mice aged P20. ROS levels were monitored using the ROS probe dihydrorhodamine 123 (DHR) and cell nuclei were labelled with Hoescht 33342. DHR relative fluorescence units (RFU) was expressed as a ratio of the Hoescht 33342 RFU in the same tissue. Data are presented as fold change (FC) relative to CON with associated standard deviation. ${ }^{*} \mathrm{P}<0.05$, one-way ANOVA t-test with post-hoc Dunnett's test, compared to genotype indicated. 
Figure 5. Oxidative stress induces cytokine expression in lens epithelial cells. Lens epithelial cells (21EM15) were treated with (A) $500 \mu \mathrm{M}$ buthionine sulfoximine (BSO) for 48 hours, (B) $25 \mu \mathrm{M} \mathrm{H} \mathrm{O}_{2}$ for 24 hours, or (C) $500 \mu \mathrm{M}$ BSO and $10 \mathrm{mM}$ $\mathrm{N}$-acetyl-L-cysteine (NAC) for 48 hours. Gene expression was determined by reverse transcriptase (RT) quantitative PCR (qPCR), as calculated by the $\triangle \mathrm{Ct}$ method. GAPDH was used as an internal normalization control. Gene expression is displayed as the average of the fold change relative to control and associated standard deviation from three independent experiments. ${ }^{*} \mathrm{P}<0.05$ Student's unpaired t-test, compared to untreated $(0 \mu \mathrm{M})$ cells. (D) ROS production was determined in $21 \mathrm{EM} 15$ cells treated with $500 \mu \mathrm{M}$ BSO for 48 hours, $25 \mu \mathrm{M} \mathrm{H} \mathrm{O}_{2}$ for 24 hours, or $500 \mu \mathrm{M} \mathrm{BSO}+10$ mM NAC for 48 hours using the ROS probe dihydrorhodamine 123 (DHR). Cell nuclei were labelled with Hoescht 33342. Images were taken with the same camera settings and magnification (200x).

Figure 6: Analysis of markers of EMT in KO lenses aged P20 and detection of markers of oxidative stress, and cytokine expression in lens epithelial explants. (A) Immunohistochemical staining for alpha-smooth muscle actin ( $\alpha$-SMA) and counterstaining with hematoxylin in the eyes of KO mice aged postnatal day (P) 1 and 20. Positive staining for $\alpha$-SMA (closed arrows) indicates cells undergoing EMT. Regions demarcated by boxes in $\mathrm{B}^{\prime}$ and $\mathrm{E}^{\prime}$ are shown in higher magnification in $\mathrm{C}^{\prime}$ and $\mathrm{F}^{\prime}$, respectively. Dashed box in $\mathrm{F}^{\prime}$ shown at 400X magnification in inset. Magnification is indicated in the lower right corner of each image. (B-E) Lens epithelial explant systems were established in normal media (OmM NAC) or media containing $10 \mathrm{mM} \mathrm{N}$-acetyl-L-cysteine (10mM NAC) and cultured for 24 hours. (B) Expression of antioxidant response element genes. (C) ROS levels were monitored by dihydrorhodamine 123 (DHR) staining. Cell nuclei were labelled with Hoescht 33342. Images were taken with the same camera settings and magnification (200x). NAC- = OmM NAC. (D) Expression of cytokines. Gene expression was determined by reverse transcriptase (RT) quantitative PCR (qPCR), as calculated by the $\triangle \mathrm{Ct}$ method. GAPDH was used as an internal normalization control. Gene expression is presented as the mean of the fold change relative to control $(0 \mu \mathrm{M} \mathrm{NAC})$ and standard deviation. ${ }^{*} \mathrm{P}<0.05$, Student's unpaired t-test, compared to OmM NAC.

Figure 7: Proposed positive feedback loop by which oxidative stress and cytokine expression promote Posterior Capsule Opacification (PCO). We propose that a positive feedback loop reinforces the development of PCO. Increased ROS-driven oxidative stress and/or increased cytokine expression not only, induce the transdifferentiation of the remaining epithelial cells into myofibroblasts (EMT) but, increase each other and together reinforce EMT. Consequently, as more of the remaining lens epithelial cells undergo EMT occurs, PCO develops. Created with bioender.com.

\section{Supplemental Figures:}


Supplemental Figure 1: Histological analysis of eyes from CON and KO mice. Tissue sections of eyes from CON and KO mice aged postnatal day (P) 1, 20 and 50 were analyzed for changes in gross morphology. Hematoxylin \& eosin staining of eyes from CON (A-F) and KO (G-M) mice. Abbreviations: C, cornea; L, lens; R, retina; V, vitreous humor. Regions demarcated by boxes in $A, C$ and $E$ are shown in higher magnification in $B, D$ and $F$, respectively. Magnification is indicated in the lower right corner of each image.

Supplemental Figure 2: Cell counts in the Aqueous and Vitreous Humors. The eyes from CON, CRE and KO mice aged P1, P20 or P50 ( $n=3)$ were sectioned, stained by H\&E and the number of cells in aqueous and vitreous humor counted. Data are presented as the mean \pm SD from 3 mice (the number of cells in the pair of eyes from each mouse were averaged). * $\mathrm{P}<0.05$, ANOVA with post-hoc Tukey's test correction, compared with CON;,$+ \mathrm{P}<0.05$, ANOVA with post-hoc Tukey's test correction, compared with CRE

\section{Supplemental Figure 3: Characterization of immune surveillance of ocular structures in the eyes of CRE mice. The eyes} from CRE mice aged postnatal day (P) 1, 21 and 50 were analyzed for the presence of cells in ocular structures. (A) Hematoxylin \& eosin (H\&E) staining at P1 ( $\left.A^{\prime}, B^{\prime}\right)$, P21 (C', D') and P50. ( $\left.E^{\prime} F^{\prime}\right)$. (B) Immunohistochemical staining against CD45 in P1 ( $\left.A^{\prime}, B^{\prime}\right)$ and P21 ( $\left.C^{\prime}, D^{\prime}\right)$ CRE mice. Closed arrows indicate leukocytes. Immunohistochemical staining against CD68 in P1 (E', $\left.F^{\prime}\right)$ and P21 (G', $\left.H^{\prime}\right)$ CRE mice. Open arrows indicate macrophages. Regions demarcated by boxes in $A^{\prime}, E^{\prime}$ and $\mathrm{G}^{\prime}$ are shown in higher magnification in $\mathrm{B}^{\prime}, \mathrm{F}^{\prime}$ and $\mathrm{H}^{\prime}$, respectively. Abbreviations: $\mathrm{C}$, cornea; $\mathrm{L}$, lens; $\mathrm{R}$, retina; $V$, vitreous humor. Magnification is indicated in the lower right corner of each image.

Supplemental Figure 4: NF-KB activation in lens epithelial cells and lenses. 21EM15 cells were treated for 48 hours with $500 \mu \mathrm{M}$ BSO and analyzed for NF-KB activation by quantifying the expression and activation (phosphorylation, P) of members of the NF-KB signaling pathway. (A) Representative Western blot of control (0 $\mu \mathrm{M} \mathrm{BSO}$ ) and treated (500 $\mu \mathrm{M}$ BSO) cells. (B) NF-KB signaling pathway protein (Ikk- $\beta, N F-\kappa \beta, I \kappa B \alpha)$ and phosphorylated protein $(P-I K B \alpha)$ expression in control and BSO-treated cells were normalized to Ponceau S stain. Data are presented as the mean and associated standard deviation from three independent experiments. No differences occurred between BSO-treated and control cells (Student's unpaired t-test, with $\mathrm{P}<0.05$ being considered significant). (C) Expression of genetic targets of NF-KB in control $(0 \mu \mathrm{M}$ BSO) and treated (500 $\mu \mathrm{M}$ BSO $\neq 21 \mathrm{EM} 15$ cells. Gene expression was determined by reverse transcriptase (RT) quantitative PCR (qPCR) with the $\triangle \mathrm{Ct}$ method and GAPDH used as an internal normalization control. Gene expression is presented as the mean fold-change relative to control with associated standard deviation from three independent experiments. No differences occurred between BSO-treated and control cells (Student's unpaired t-test, with $\mathrm{P}<0.05$ being considered significant). (D) RNA-seq box plots indicating variance stabilizing transformed (VST) normalized count data for genetic targets of NF-KB in the lenses of KO mice compared with the lenses of CON mice aged P1. VST count data are shown as mean (thin horizontal bar) \pm standard deviation (error bar). Significance was evaluated at $P<0.05$ and determined by the Benjamini-Hochberg method. 
Supplemental Figure 5: Analysis of a marker of EMT in the lenses of CRE mice aged P1 and P21. Immunohistochemical staining for $\alpha$-SMA (closed arrows) and counterstaining with hematoxylin in the eyes of CRE mice aged postnatal day (P) $1(\mathrm{~A}, \mathrm{~B})$ and $21(\mathrm{C}-\mathrm{F})$. Regions demarcated by boxes in $\mathrm{A}, \mathrm{C}$ and $\mathrm{E}$ are shown in higher magnification in $\mathrm{B}, \mathrm{D}$ and $\mathrm{F}$, respectively. Magnification is indicated in the lower right corner of each image.

Supplemental Figure 6: Analysis of EMT-related genes in lens epithelial explants. Lens epithelial explant systems were established in normal media or media containing $10 \mathrm{mM} \mathrm{N}$-Acetyl-L-cysteine (NAC) and cultured for 24 hours. Gene expression was determined by reverse transcriptase (RT) quantitative PCR (qPCR), as calculated by the $\Delta C t$ method. GAPDH was used as an internal normalization control. Gene expression is displayed as the average of the fold change relative to control and associated standard deviation. * P-value $<0.05$ Student's unpaired t-test, compared to untreated (0 mM) explants.

Supplemental Figure 7: Analysis of cytokine expression in lens epithelial explants. Lens epithelial explant systems were established in normal media (OmM NAC) or media containing $10 \mathrm{mM} \mathrm{N}$-Acetyl-L-cysteine (10mM NAC) and cultured for 24 hours. Gene expression was determined by reverse transcriptase (RT) quantitative PCR (qPCR), as calculated by the $\Delta C t$ method. GAPDH was used as an internal normalization control. Gene expression is displayed as the average of the foldchange relative to control, with associated standard deviation. ${ }^{*} \mathrm{P}<0.05$. Student's unpaired t-test, compared to untreated $(0 \mathrm{mM})$ explants.

Supplemental Table 1: Primers used for RT-qPCR

\begin{tabular}{|l|l|l|}
\hline Gene & Forward Primer & Reverse Primer \\
\hline Acta2 & GTGAAGAGGAAGACAGCACAG & GCCCATTCCAACCATTACTCC \\
\hline Ccl2 & GTCCCTGTCATGCTTCTGG & GCTCTCCAGCCTACTCATTG \\
\hline Ccl4 & AAACCTAACCCCGAGCAAC & CGGGAGGTGTAAGAGAAACAG \\
\hline Ccl7 & TCTCTCACTCTCTTTCTCCACC & GGGATCTTTTGTTTCTTGACATAGC \\
\hline Csf1 & TGATTGGGAATGGACACCTG & CAGCTGTTCCTGGTCTACAAA \\
\hline Cxcl1 & AGAACATCCAGAGCTTGAAGG & CAATTTTCTGAACCAAGGGAGC \\
\hline Cxcl12 & ACTCCAAACTGTGCCCTTC & AAGCTTTCTCCAGGTACTCTTG \\
\hline Cxcl16 & GTTGCAGTCCAAAAGCGTG & GTCTGGGTACTGGCTTGAG \\
\hline Gapdh & TTGATGGCAACAATCTCCAC & CGTCCCGTAACAAAATGGT \\
\hline Gclc & GTCTCAAGAACATCGCCTCC & CTGCACATCTACCACGCAGT \\
\hline Gdf15 & GAGAGGACTCGAACTCAGAAC & GACCCCAATCTCACCTCTG \\
\hline
\end{tabular}


bioRxiv preprint doi: https://doi.org/10.1101/2021.10.16.464542; this version posted October 16, 2021. The copyright holder for this preprint (which was not certified by peer review) is the author/funder, who has granted bioRxiv a license to display the preprint in perpetuity. It is made available under aCC-BY 4.0 International license.

\begin{tabular}{|l|l|l|}
\hline Hif1a & TGCCACTTCCCCACAATG & GTCCATCTGTGCCTTCATCTC \\
\hline Hmox1 & TCAAGGCCTCAGACAAATCC & ACAACCAGTGAGTGGAGCCCT \\
\hline Ptprc & CCTTTGGATTTGCCCTTCTG & TCGTTGTGGTAGCTATGGTTG \\
\hline
\end{tabular}

Supplemental Table 2: Top 25 upregulated genes in the lenses of KO mice aged P1 compared with lenses from similarly aged CON mice.

\begin{tabular}{|l|r|r|}
\hline Gene Symbol & log2FC & adjusted P value $^{\mathbf{b}}$ \\
\hline Arg1 & 7.411177 & $2.10 \mathrm{E}-56$ \\
\hline Ptgs2 & 7.235448 & $2.57 \mathrm{E}-38$ \\
\hline 3300005D01Rik & 6.342014 & $1.10 \mathrm{E}-25$ \\
\hline Cdsn & 6.030009 & $7.87 \mathrm{E}-22$ \\
\hline Slc14a1 & 6.014576 & $2.95 \mathrm{E}-22$ \\
\hline Ccl7 & 5.991658 & $8.79 \mathrm{E}-83$ \\
\hline Rbp4 & 5.704899 & $3.70 \mathrm{E}-28$ \\
\hline Cdkn1a & 5.680406 & $3.39 \mathrm{E}-57$ \\
\hline Dglucy & 5.623126 & $1.75 \mathrm{E}-18$ \\
\hline Arr3 & 5.587417 & $7.37 \mathrm{E}-22$ \\
\hline Cc14 & 5.574396 & $3.39 \mathrm{E}-18$ \\
\hline Ccdc141 & 5.544726 & $1.31 \mathrm{E}-19$ \\
\hline Ch25h & 5.454229 & $3.18 \mathrm{E}-16$ \\
\hline Gdf15 & 5.42999 & $1.97 \mathrm{E}-26$ \\
\hline Cd300ld & 5.392139 & $1.97 \mathrm{E}-16$ \\
\hline Car2 & 5.338622 & $1.52 \mathrm{E}-70$ \\
\hline Cxcl16 & 5.274513 & $1.15 \mathrm{E}-15$ \\
\hline Clrn2 & 5.215495 & $3.66 \mathrm{E}-18$ \\
\hline Fgl2 & 5.134096 & $1.78 \mathrm{E}-15$ \\
\hline Tns4 & 5.082742 & $3.80 \mathrm{E}-14$ \\
\hline Adrb2 & 5.044112 & $2.34 \mathrm{E}-40$ \\
\hline Cd300lb & 5.007534 & $2.49 \mathrm{E}-13$ \\
\hline S1pr2 & 4.960696 & $2.49 \mathrm{E}-13$ \\
\hline Slc37a2 & 4.801622 & $4.07 \mathrm{E}-12$ \\
\hline Dusp10 & 4.792521 & $8.03 \mathrm{E}-13$ \\
\hline
\end{tabular}

${ }^{\mathrm{a}} \log 2 \mathrm{FC}=\mathrm{KO}$ compared with CON

${ }^{\mathrm{b}}$ adjusted $\mathrm{P}$ value $=$ Benjamini-Hochberg method

\section{References}

1. Lutty, G.A. and D.S. McLeod, Development of the hyaloid, choroidal and retinal vasculatures in the fetal human eye. Progress in Retinal and Eye Research, 2018. 62: p. 58-76.

2. Zhang, H., et al., Novel Discovery of LYVE-1 Expression in the Hyaloid Vascular System. Investigative Ophthalmology \& Visual Science, 2010. 51(12): p. 6157-6161. 
3. Lang, R.A. and J.M. Bishop, Macrophages are required for cell death and tissue remodeling in the developing mouse eye. Cell, 1993. 74(3): p. 453-462.

4. Cuthbertson, R.A. and R.A. Lang, Developmental ocular disease in GM-CSF transgenic mice is mediated by autostimulated macrophages. Developmental Biology, 1989. 134(1): p. 119-129.

5. Nishitani, K. and K. Sasaki, Macrophage localization in the developing lens primordium of the mouse embryo - An immunohistochemical study. Experimental Eye Research, 2006. 83(1): p. 223-228.

6. Logan, C.M., C.J. Bowen, and A.S. Menko, Induction of Immune Surveillance of the Dysmorphogenic Lens. Scientific Reports, 2017. 7(1): p. 16235.

7. Jiang, J., et al., Lens Epithelial Cells Initiate an Inflammatory Response Following Cataract Surgery. Investigative Ophthalmology \& Visual Science, 2018. 59(12): p. 4986-4997.

8. DeDreu, J., et al., An immune response to the avascular lens following wounding of the cornea involves ciliary zonule fibrils. The FASEB Journal, 2020. 34(7): p. 9316-9336.

9. Menko, A.S., et al., Resident immune cells of the avascular lens: Mediators of the injury and fibrotic response of the lens. The FASEB Journal, 2021. 35(4): p. e21341.

10. Sies, H., Oxidative stress: a concept in redox biology and medicine. Redox Biology, 2015. 4: p. 180-183.

11. Morgan, M.J. and Z.-g. Liu, Crosstalk of reactive oxygen species and NF-KB signaling. Cell Research, 2011. 21(1): p. 103-115.

12. Lawrence, T., The Nuclear Factor NF-KB Pathway in Inflammation. Cold Spring Harbor Perspectives in Biology, 2009. 1(6).

13. Blaser, H., et al., TNF and ROS Crosstalk in Inflammation. Trends in Cell Biology, 2016. 26(4): p. 249-261.

14. Wishart, T.F.L., et al., Hallmarks of lens aging and cataractogenesis. Experimental Eye Research, 2021. 210: p. 108709.

15. Lou, M.F., Redox regulation in the lens. Progress in Retinal and Eye Research, 2003. 22(5): p. 657-682.

16. Robinson, J.M., Reactive oxygen species in phagocytic leukocytes. Histochemistry and Cell Biology, 2008. 130(2): p. 281.

17. Wei, Z., et al., Reduced Glutathione Level Promotes Epithelial-Mesenchymal Transition in Lens Epithelial Cells via a Wnt/6-Catenin-Mediated Pathway: Relevance for Cataract Therapy. The American Journal of Pathology, 2017. 187(11): p. 2399-2412.

18. Chamberlain, C.G., K.J. Mansfield, and A. Cerra, Glutathione and catalase suppress TGFbeta-induced cataractrelated changes in cultured rat lenses and lens epithelial explants. Molecular vision, 2009. 15: p. 895-905.

19. Whitson, J.A., et al., Transcriptome of the GSH-Depleted Lens Reveals Changes in Detoxification and EMT Signaling Genes, Transport Systems, and Lipid Homeostasis. Investigative Ophthalmology \& Visual Science, 2017. 58(5): p. 2666-2684.

20. Whitson, J.A., et al., Proteomic analysis of the glutathione-deficient LEGSKO mouse lens reveals activation of EMT signaling, loss of lens specific markers, and changes in stress response proteins. Free Radical Biology and Medicine, 2017. 113: p. 84-96.

21. Thompson, B., et al., Impaired GSH biosynthesis disrupts eye development, lens morphogenesis and PAX6 function. The Ocular Surface, 2021. 22: p. 190-203.

22. Chen, Y., et al., Hepatocyte-specific Gclc deletion leads to rapid onset of steatosis with mitochondrial injury and liver failure. Hepatology, 2007. 45(5): p. 1118-28.

23. Ashery-Padan, R., et al., Pax6 activity in the lens primordium is required for lens formation and for correct placement of a single retina in the eye. Genes \& Development, 2000. 14(21): p. 2701-2711.

24. Afgan, E., et al., The Galaxy platform for accessible, reproducible and collaborative biomedical analyses: 2016 update. Nucleic acids research, 2016. 44(W1): p. W3-W10.

25. Bolger, A.M., M. Lohse, and B. Usadel, Trimmomatic: a flexible trimmer for Illumina sequence data. Bioinformatics (Oxford, England), 2014. 30(15): p. 2114-2120.

26. Kim, D., B. Langmead, and S.L. Salzberg, HISAT: a fast spliced aligner with low memory requirements. Nature methods, 2015. 12(4): p. 357-360.

27. Liao, Y., G.K. Smyth, and W. Shi, featureCounts: an efficient general purpose program for assigning sequence reads to genomic features. Bioinformatics, 2014. 30(7): p. 923-930.

28. Love, M.I., W. Huber, and S. Anders, Moderated estimation of fold change and dispersion for RNA-seq data with DESeq2. Genome biology, 2014. 15(12): p. 550-550.

29. Benjamini, Y. and Y. Hochberg, Controlling the False Discovery Rate: A Practical and Powerful Approach to Multiple Testing. Journal of the Royal Statistical Society: Series B (Methodological), 1995. 57(1): p. 289-300. 
30. Huang, D.W., B.T. Sherman, and R.A. Lempicki, Systematic and integrative analysis of large gene lists using DAVID bioinformatics resources. Nature Protocols, 2009. 4(1): p. 44-57.

31. Girish, V. and A. Vijayalakshmi, Affordable image analysis using NIH Image/ImageJ. Indian J Cancer, 2004. 41(1): p. 47.

32. $\mathrm{Li}, \mathrm{X}$., et al., L-carnitine alleviates oxidative stress-related damage via MAPK signaling in human lens epithelial cells exposed to H2O2. Int J Mol Med, 2019. 44(4): p. 1515-1522.

33. Sun, Y., et al., Glutathione depletion induces ferroptosis, autophagy, and premature cell senescence in retinal pigment epithelial cells. Cell Death \& Disease, 2018. 9(7): p. 753.

34. Zelenka, P.S., C.Y. Gao, and S.S. Saravanamuthu, Preparation and Culture of Rat Lens Epithelial Explants for Studying Terminal Differentiation. JoVE, 2009(31): p. e1519.

35. West-Mays, J.A., G. Pino, and F.J. Lovicu, Development and use of the lens epithelial explant system to study lens differentiation and cataractogenesis. Progress in Retinal and Eye Research, 2010. 29(2): p. 135-143.

36. Livak, K.J. and T.D. Schmittgen, Analysis of Relative Gene Expression Data Using Real-Time Quantitative PCR and the 2- $\triangle \triangle C T$ Method. Methods, 2001. 25(4): p. 402-408.

37. Pendergrass, W., et al., Accumulation of DNA, Nuclear and Mitochondrial Debris, and ROS at Sites of Age-Related Cortical Cataract in Mice. Investigative Ophthalmology \& Visual Science, 2005. 46(12): p. 4661-4670.

38. Western Blotting - A Beginner's Guide, Abcam, Editor.

39. Lam, P.T., et al., Considerations for the use of Cre recombinase for conditional gene deletion in the mouse lens. Human Genomics, 2019. 13(1): p. 10.

40. Raghunath, A., et al., Antioxidant response elements: Discovery, classes, regulation and potential applications. Redox Biology, 2018. 17: p. 297-314.

41. Terrell, A.M., et al., Molecular characterization of mouse lens epithelial cell lines and their suitability to study RNA granules and cataract associated genes. Experimental Eye Research, 2015. 131: p. 42-55.

42. Dudek, E.J., F. Shang, and A. Taylor, H2O2-mediated oxidative stress activates NF-KB in lens epithelial cells. Free Radical Biology and Medicine, 2001. 31(5): p. 651-658.

43. Srivastava, S.K. and K.V. Ramana, Focus on Molecules: Nuclear factor-kappaB. Experimental Eye Research, 2009. 88(1): p. 2-3.

44. Lingappan, K., NF-KB in oxidative stress. Current Opinion in Toxicology, 2018. 7: p. 81-86.

45. Liu, T., et al., NF-KB signaling in inflammation. Signal Transduction and Targeted Therapy, 2017. 2(1): p. 17023.

46. Basu, S., S. Rajakaruna, and A.S. Menko, Insulin-like Growth Factor Receptor-1 and Nuclear Factor $\kappa B$ Are Crucial Survival Signals That Regulate Caspase-3-mediated Lens Epithelial Cell Differentiation Initiation*. Journal of Biological Chemistry, 2012. 287(11): p. 8384-8397.

47. Li, C., et al., GDF15 promotes EMT and metastasis in colorectal cancer. Oncotarget, 2015. 7(1).

48. $\mathrm{Li}, \mathrm{X}$., et al., A CCL2/ROS autoregulation loop is critical for cancer-associated fibroblasts-enhanced tumor growth of oral squamous cell carcinoma. Carcinogenesis, 2014. 35(6): p. 1362-1370.

49. Li, J., et al., JNK1/8-catenin axis regulates H2O2-induced epithelial-to-mesenchymal transition in human lens epithelial cells. Biochemical and Biophysical Research Communications, 2019. 511(2): p. 336-342.

50. Walker, J.L. and A.S. Menko, Immune cells in lens injury repair and fibrosis. Experimental Eye Research, 2021. 209: p. 108664.

51. Upreti, A., et al., Transcriptome analysis of lens epithelial explants upon vitreous-induced fiber cell differentiation. Investigative Ophthalmology \& Visual Science, 2021. 62(8): p. 2083-2083.

52. Osada, H., et al., Ultraviolet B-induced expression of amphiregulin and growth differentiation factor 15 in human lens epithelial cells. Molecular vision, 2011. 17: p. 159-169.

53. Borish, L.C. and J.W. Steinke, 2. Cytokines and chemokines. Journal of Allergy and Clinical Immunology, 2003. 111(2, Supplement 2): p. S460-S475.

54. Asensio, V.C., et al., C10 Is a Novel Chemokine Expressed in Experimental Inflammatory Demyelinating Disorders that Promotes Recruitment of Macrophages to the Central Nervous System. The American Journal of Pathology, 1999. 154(4): p. 1181-1191.

55. Bystry, R.S., et al., B cells and professional APCs recruit regulatory T cells via CCL4. Nature Immunology, 2001. 2(12): p. 1126-1132.

56. Proost, P., A. Wuyts, and J. van Damme, Human monocyte chemotactic proteins-2 and -3: structural and functional comparison with MCP-1. Journal of Leukocyte Biology, 1996. 59(1): p. 67-74.

57. Gschwandtner, M., R. Derler, and K.S. Midwood, More Than Just Attractive: How CCL2 Influences Myeloid Cell Behavior Beyond Chemotaxis. Frontiers in Immunology, 2019. 10(2759). 
58. Bleul, C.C., et al., A highly efficacious lymphocyte chemoattractant, stromal cell-derived factor 1 (SDF-1). Journal of Experimental Medicine, 1996. 184(3): p. 1101-1109.

59. Zhao, Y., D. Zheng, and A. Cvekl, Profiling of chromatin accessibility and identification of general cis-regulatory mechanisms that control two ocular lens differentiation pathways. Epigenetics \& Chromatin, 2019. 12(1): p. 27.

60. Hoang, T.V., et al., Comparative transcriptome analysis of epithelial and fiber cells in newborn mouse lenses with RNA sequencing. Molecular vision, 2014. 20: p. 1491-1517.

61. Zhao, Y., D. Zheng, and A. Cvekl, A comprehensive spatial-temporal transcriptomic analysis of differentiating nascent mouse lens epithelial and fiber cells. Experimental Eye Research, 2018. 175: p. 56-72.

62. García-Giménez, J.-L., et al., Oxidative stress-mediated alterations in histone post-translational modifications. Free Radical Biology and Medicine, 2021. 170: p. 6-18.

63. Tomita, K., P.J. Barnes, and I.M. Adcock, The effect of oxidative stress on histone acetylation and IL-8 release. Biochemical and Biophysical Research Communications, 2003. 301(2): p. 572-577.

64. Ito, K., et al., Cigarette smoking reduces histone deacetylase 2 expression, enhances cytokine expression, and inhibits glucocorticoid actions in alveolar macrophages. The FASEB Journal, 2001. 15(6): p. 1110-1112.

65. Gilmour, P.S., et al., Histone acetylation regulates epithelial IL-8 release mediated by oxidative stress from environmental particles. American Journal of Physiology-Lung Cellular and Molecular Physiology, 2003. 284(3): p. L533-L540.

66. Rahman, I., et al., Oxidative stress and TNF-a induce histone Acetylation and NF-KB/AP-1 activation in Alveolar epithelial cells: Potential mechanism In gene transcription in lung inflammation, in Oxygen/Nitrogen Radicals: Cell Injury and Disease, V. Vallyathan, X. Shi, and V. Castranova, Editors. 2002, Springer US: Boston, MA. p. 239-248.

67. Tigano, M., et al., Nuclear sensing of breaks in mitochondrial DNA enhances immune surveillance. Nature, 2021. 591(7850): p. 477-481.

68. Szczesny, B., et al., Mitochondrial DNA damage and subsequent activation of Z-DNA binding protein 1 links oxidative stress to inflammation in epithelial cells. Scientific Reports, 2018. 8(1): p. 914.

69. Winterberg, P.D., et al., Reactive oxygen species and IRF1 stimulate IFN $\alpha$ production by proximal tubules during ischemic AKI. American Journal of Physiology-Renal Physiology, 2013. 305(2): p. F164-F172.

70. Catani, M.V., et al., Nuclear factor $\mathrm{kB}$ and activating protein 1 are involved in differentiation-related resistance to oxidative stress in skeletal muscle cells. Free Radical Biology and Medicine, 2004. 37(7): p. 1024-1036.

71. Zgheib, C., et al., Acyloxy Nitroso Compounds Inhibit LIF Signaling in Endothelial Cells and Cardiac Myocytes: Evidence That STAT3 Signaling Is Redox-Sensitive. PLOS ONE, 2012. 7(8): p. e43313.

72. Biswas, S.K., Does the Interdependence between Oxidative Stress and Inflammation Explain the Antioxidant Paradox? Oxidative Medicine and Cellular Longevity, 2016. 2016: p. 5698931.

73. Zheng, $Q$., et al., Reactive oxygen species activated NLRP3 inflammasomes initiate inflammation in hyperosmolarity stressed human corneal epithelial cells and environment-induced dry eye patients. Experimental Eye Research, 2015. 134: p. 133-140.

74. Liu, Y.-C., et al., Changes in aqueous oxidative stress, prostaglandins, and cytokines: Comparisons of low-energy femtosecond laser-assisted cataract surgery versus conventional phacoemulsification. Journal of Cataract \& Refractive Surgery, 2019. 45(2).

75. Taravati, P., et al., Postcataract surgical inflammation. Current Opinion in Ophthalmology, 2012. 23(1).

76. Dua, H. and R. Attre, Treatment of Post-operative inflammation following Cataract Surgery - A Review. European Ophthalmic Review, 2012. 6(2): p. 98-103.

77. Müllner-Eidenböck, A., et al., Cellular reaction on the anterior surface of 4 types of intraocular lenses. Journal of Cataract \& Refractive Surgery, 2001. 27(5).

78. Baum, J. and H.S. Duffy, Fibroblasts and Myofibroblasts: What Are We Talking About? Journal of Cardiovascular Pharmacology, 2011. 57(4).

79. Krausgruber, T., et al., Structural cells are key regulators of organ-specific immune responses. Nature, 2020. 583(7815): p. 296-302.

80. Medvedovic, M., et al., Gene expression and discovery during lens regeneration in mouse: regulation of epithelial to mesenchymal transition and lens differentiation. Mol Vis, 2006. 12: p. 422-40.

81. Li, Y., et al., Macrophage recruitment in immune-privileged lens during capsule repair, necrotic fiber removal, and fibrosis. iScience, 2021. 24(6): p. 102533.

82. Shu, D.Y. and F.J. Lovicu, Myofibroblast transdifferentiation: The dark force in ocular wound healing and fibrosis. Progress in Retinal and Eye Research, 2017. 60: p. 44-65.

83. Walker, J.L., et al., Unique precursors for the mesenchymal cells involved in injury response and fibrosis. Proceedings of the National Academy of Sciences, 2010. 107(31): p. 13730. 
84. Wallentin, N., B. Lundgren, and C. Lundberg, Lack of correlation between intraocular inflammation and aftercataract formation in the rabbit eye. Journal of Cataract \& Refractive Surgery, 2000. 26(9).

85. Symonds, J.G., F.J. Lovicu, and C.G. Chamberlain, Differing effects of dexamethasone and diclofenac on posterior capsule opacification-like changes in a rat lens explant model. Experimental Eye Research, 2006. 83(4): p. 771782.

86. Laurell, C.G. and C. Zetterström, Effects of dexamethasone, diclofenac, or placebo on the inflammatory response after cataract surgery. British Journal of Ophthalmology, 2002. 86(12): p. 1380.

87. Hecht, I., et al., Anti-inflammatory Medication After Cataract Surgery and Posterior Capsular Opacification. American Journal of Ophthalmology, 2020. 215: p. 104-111.

88. Nibourg, L.M., et al., Prevention of posterior capsular opacification. Experimental Eye Research, 2015. 136: p. 100115.

89. Zaczek, A., C.-G. Laurell, and C. Zetterström, Posterior capsule opacification after phacoemulsification in patients with postoperative steroidal and nonsteroidal treatment. Journal of Cataract \& Refractive Surgery, 2004. 30(2).

90. Adachi, M., et al., Nonsteroidal anti-inflammatory drugs and oxidative stress in cancer cells. Histology and histopathology, 2007. 22(4): p. 437-442.

91. Liu, W., et al., Dexamethasone-induced production of reactive oxygen species promotes apoptosis via endoplasmic reticulum stress and autophagy in MC3T3-E1 cells. Int J Mol Med, 2018. 41(4): p. 2028-2036.

92. Feng, Y.-L. and X.-L. Tang, Effect of glucocorticoid-induced oxidative stress on the expression of Cbfa1. ChemicoBiological Interactions, 2014. 207: p. 26-31.

93. Schäfer, S.C., et al., Dexamethasone suppresses eNOS and CAT-1 and induces oxidative stress in mouse resistance arterioles. American Journal of Physiology-Heart and Circulatory Physiology, 2005. 288(1): p. H436-H444.

94. Smith, A.J.O., J.A. Eldred, and I.M. Wormstone, Resveratrol Inhibits Wound Healing and Lens Fibrosis: A Putative Candidate for Posterior Capsule Opacification Prevention. Investigative Ophthalmology \& Visual Science, 2019. 60(12): p. 3863-3877.

95. Ursell, P.G., et al., 5 year incidence of YAG capsulotomy and PCO after cataract surgery with single-piece monofocal intraocular lenses: a real-world evidence study of 20,763 eyes. Eye, 2020. 34(5): p. 960-968. 
bioRxiv preprint doi: https://doi.org/10.1101/2021.10.16.464542; this version posted October 16, 2021. The copyright holder for this preprint (which was not certified by peer review) is the author/funder, who has granted bioRxiv a license to display the preprint in perpetuity. It is made Figure 1. available under aCC-BY 4.0 International license.

799

800

801

802

803

804

805

806

807

808

809

810
A
KO vs. CON

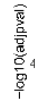
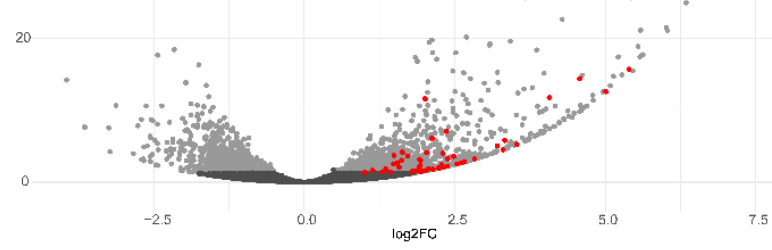
-log10(P-Value)

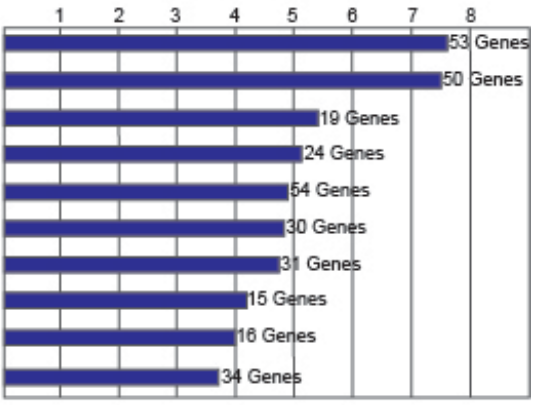

C

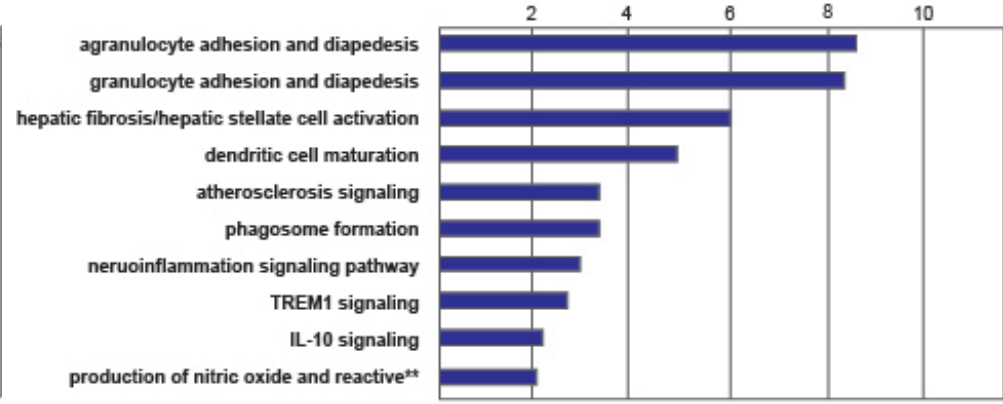

Canonical Pathways -log(P-Value)
D
Clemolines

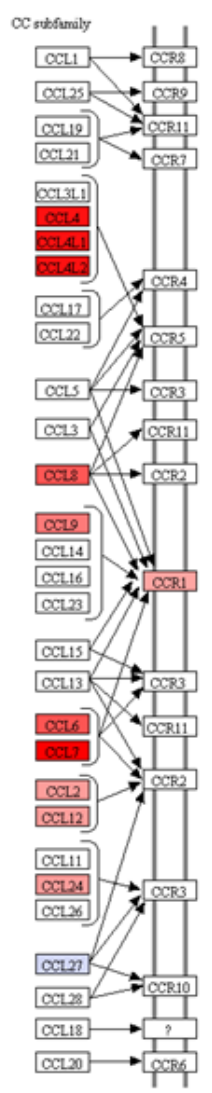

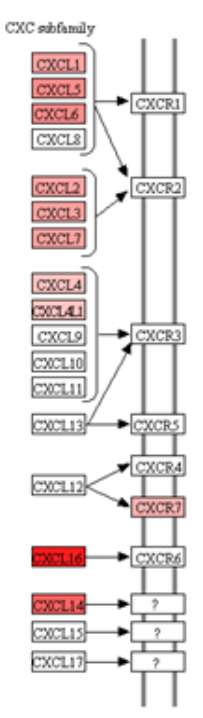
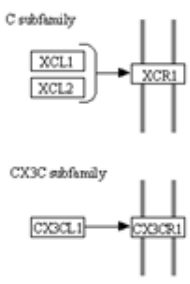

The chas I le kix al cyolidines
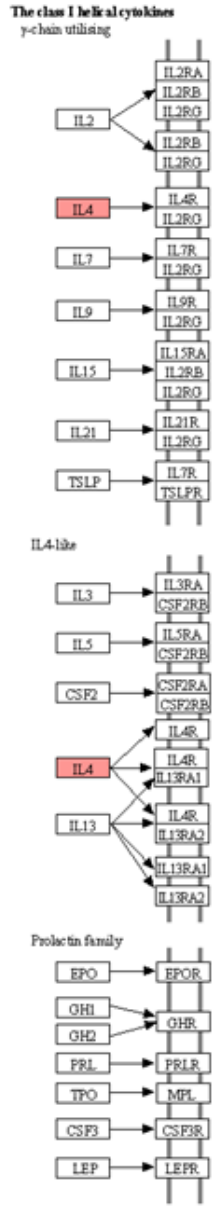

12012-12.

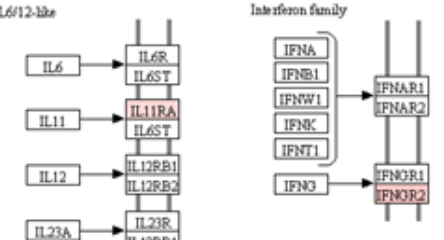

L1.-Dec cylokines

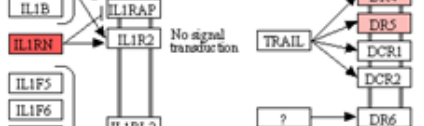

IIIFS

ILIF6

IIIFS

[L1F7

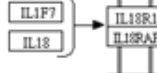

$\longrightarrow \frac{1133-1212}{\pi 12 A P}$

The class II helkal eytokines

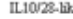

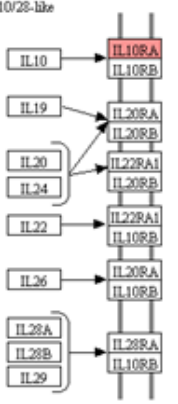

nNF Famaly

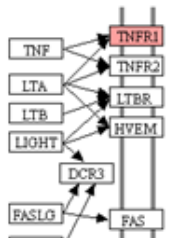

$\mathrm{FEOI} \rightarrow \mathrm{DP3}$

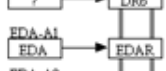

$\frac{11}{\mathrm{EDA}-\mathrm{A}^{2}} \rightarrow \frac{1}{\mathrm{XEDAB}}$

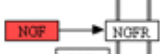

OPC

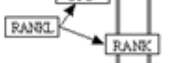

TWENK $\longrightarrow$ FN14

$\mathrm{CDN} \longrightarrow \mathrm{CD2}$

$\longrightarrow \mathrm{CDOa}$

$C 0040 \rightarrow C D A 0$

$4 \mathrm{IBEL} \longrightarrow 4 \mathrm{IBB}$

$\cos -4 t \longrightarrow 0 \times 40$

OITRL $\rightarrow$ oIm

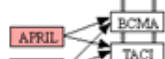

BAF $=\frac{1}{1 \text { TACI }}$

Nonchasifor

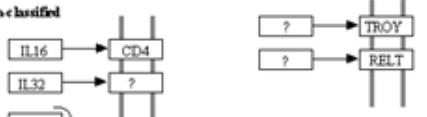

TGF P handy

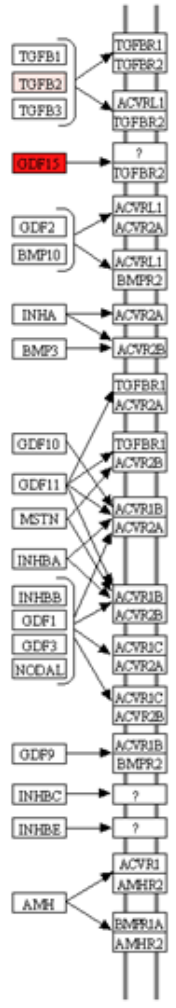

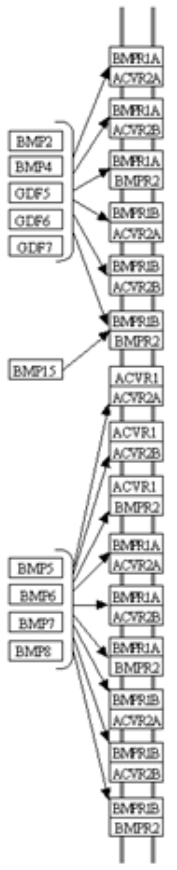


bioRxiv preprint doi: https://doi.org/10.1101/2021.10.16.464542; this version posted October 16, 2021. The copyright holder for this preprint

(which was not certified by peer review) is the author/funder, who has granted bioRxiv a license to display the preprint in perpetuity. It is made available under aCC-BY 4.0 International license.

Figure 2.

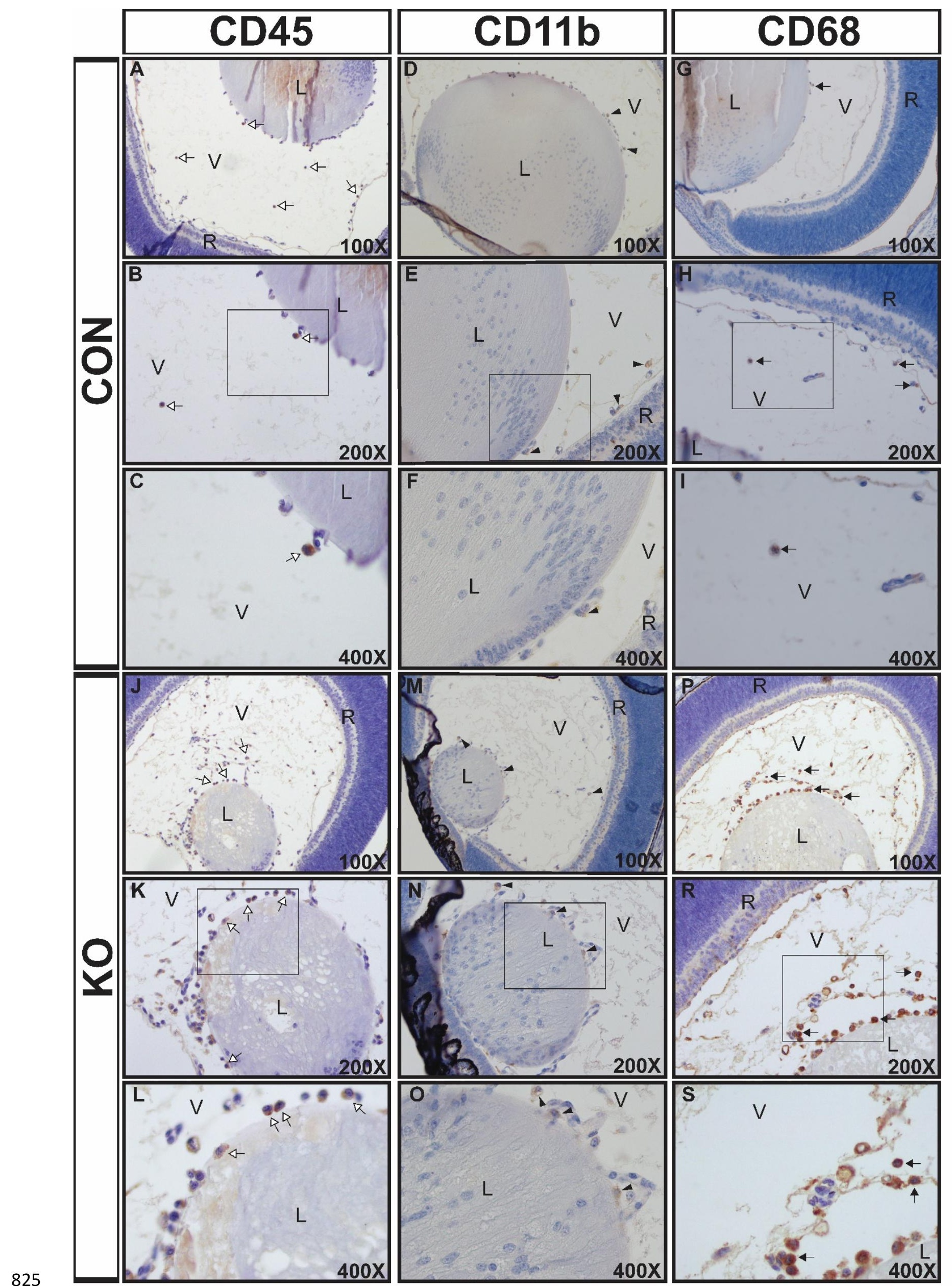


bioRxiv preprint doi: https://doi.org/10.1101/2021.10.16.464542; this version posted October 16, 2021. The copyright holder for this preprint (which was not certified by peer review) is the author/funder, who has granted bioRxiv a license to display the preprint in perpetuity. It is made available under aCC-BY 4.0 International license.

\section{Figure 3.}
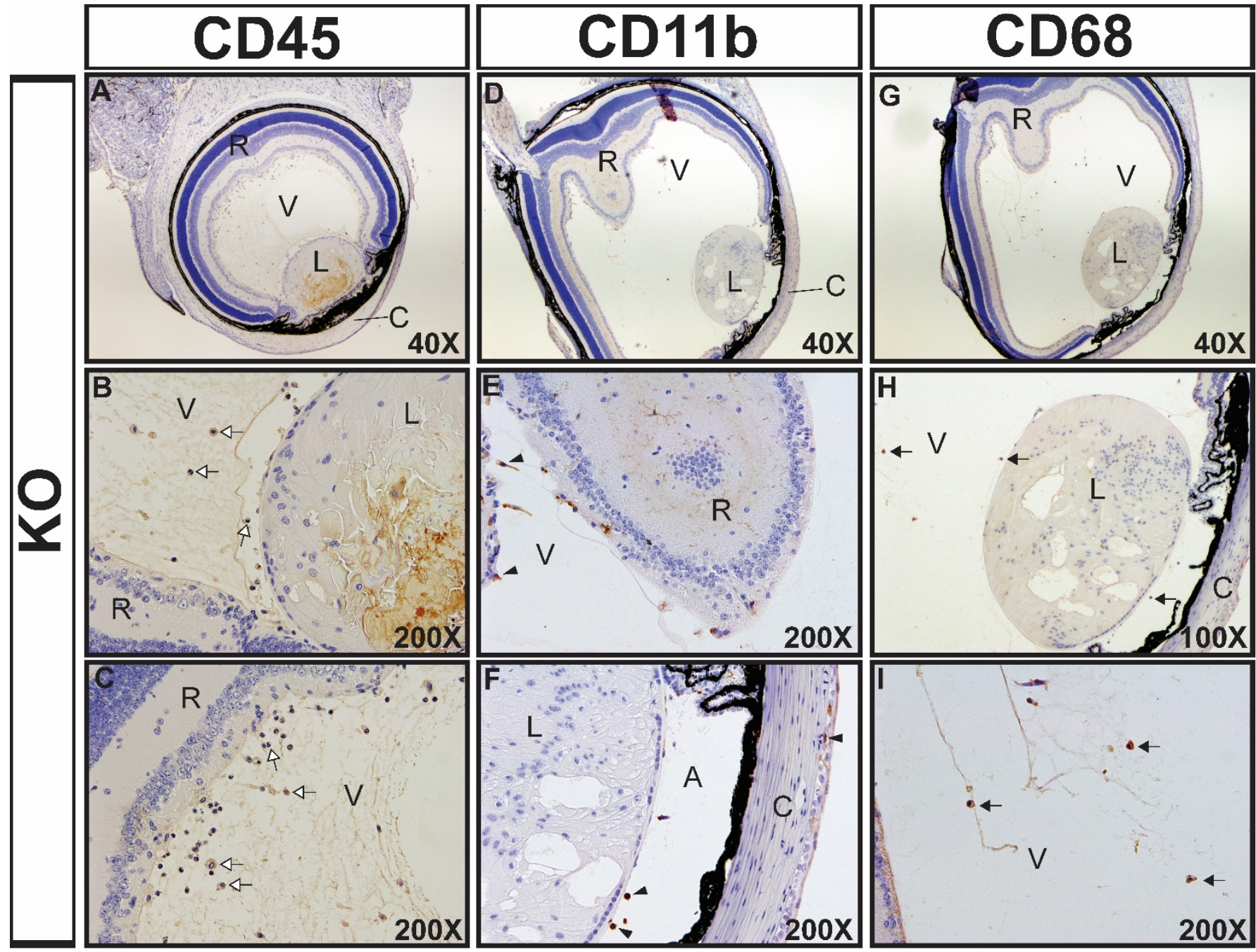

828

829

830

831

832

833

834

835

836 
Figure 4.

A

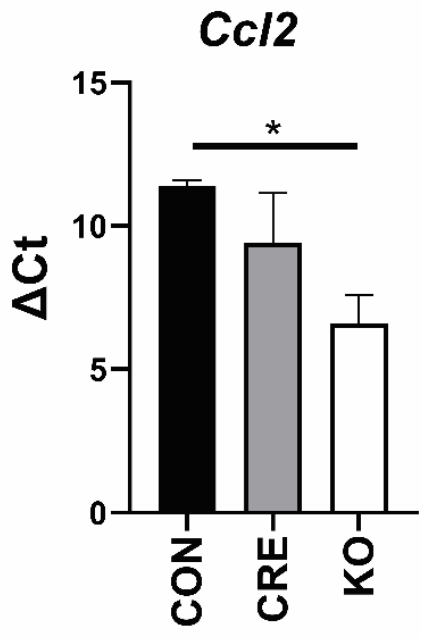

Cxcl16

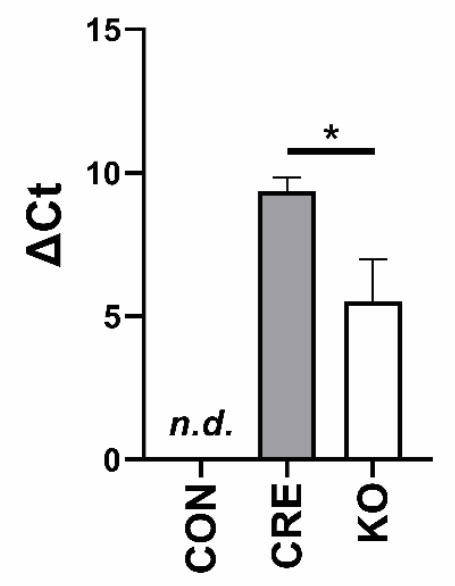

Cc/4

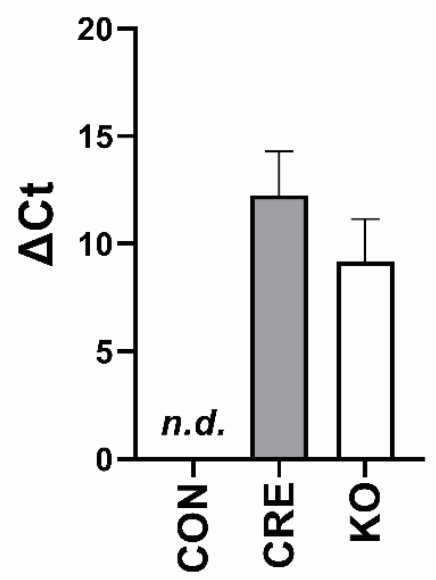

Gdf15

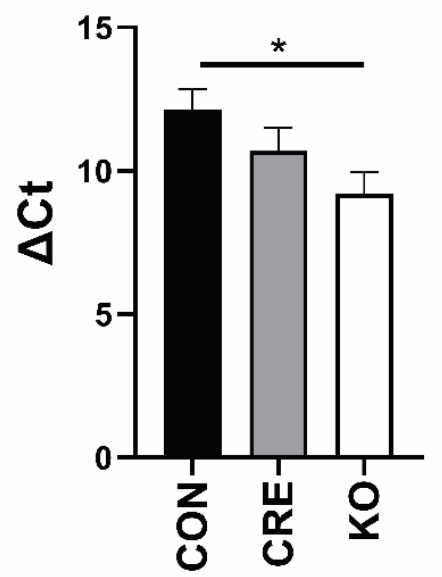

B

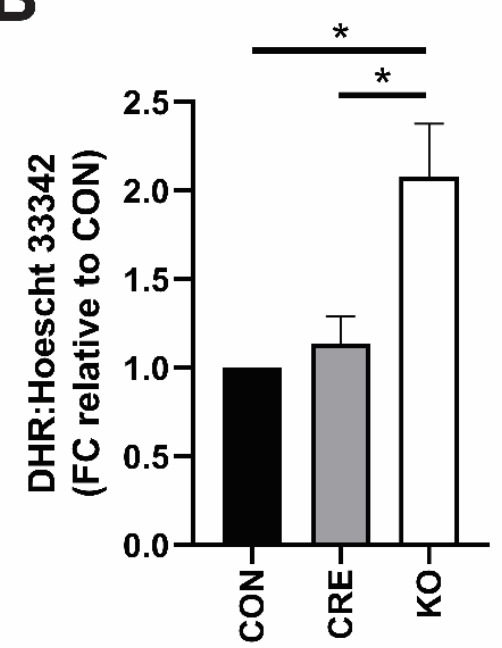

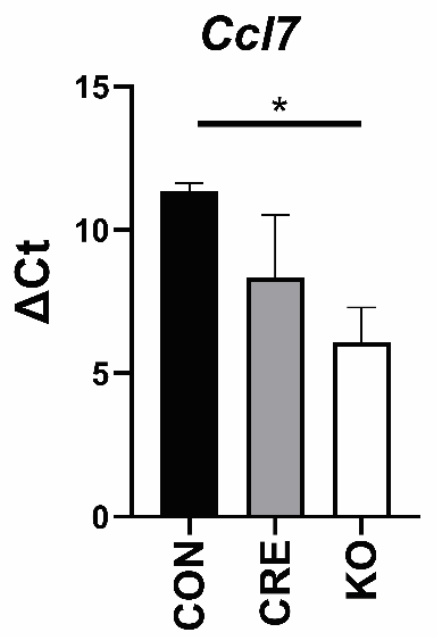

Ptprc

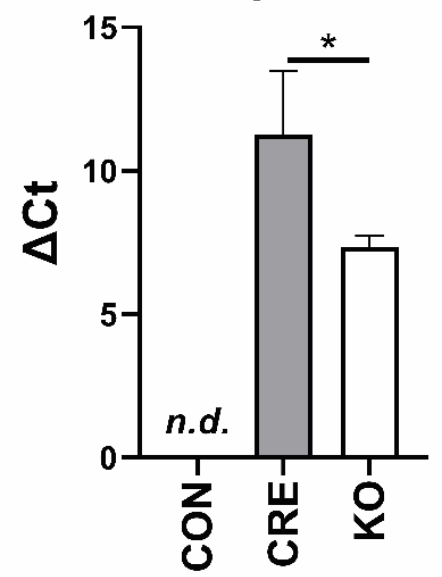




\section{Figure 5.}

\section{A}
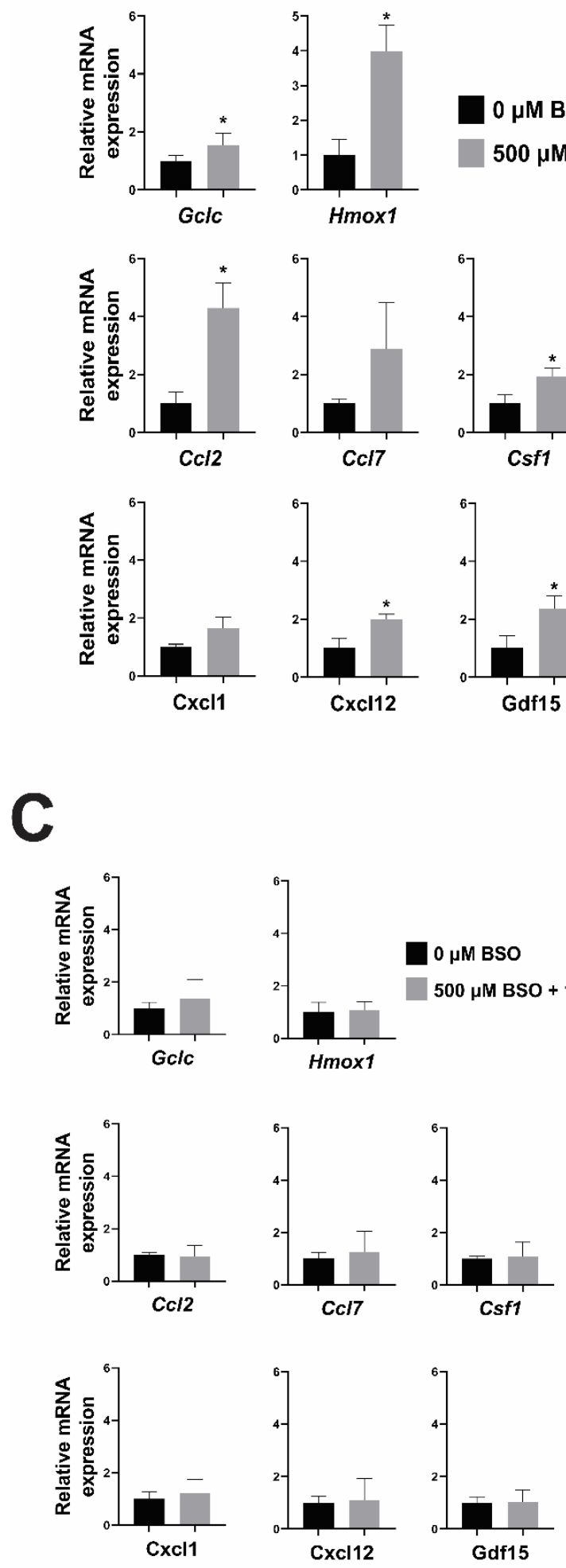

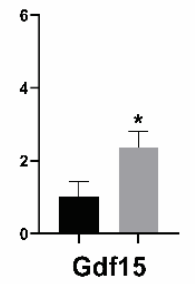

$0 \mu \mathrm{M}$ BSO

$500 \mu \mathrm{M}$ BSO

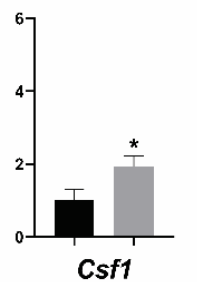

$0 \mu \mathrm{M}$ BSO

$500 \mu \mathrm{M} B S O+10 \mathrm{mM} \mathrm{NAC}$

D

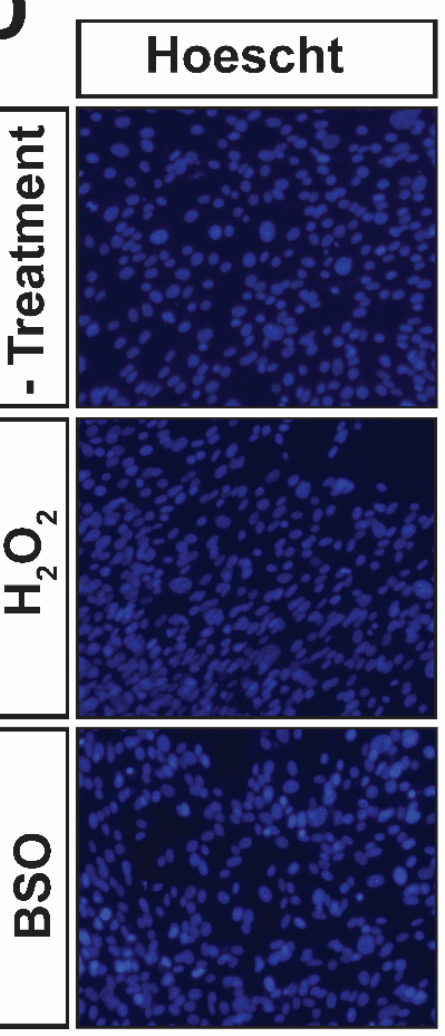

$0 \mu \mathrm{M} \mathrm{H}_{2} \mathrm{O}_{2}$

$25 \mu \mathrm{M} \mathrm{H}_{2} \mathrm{O}_{2}$
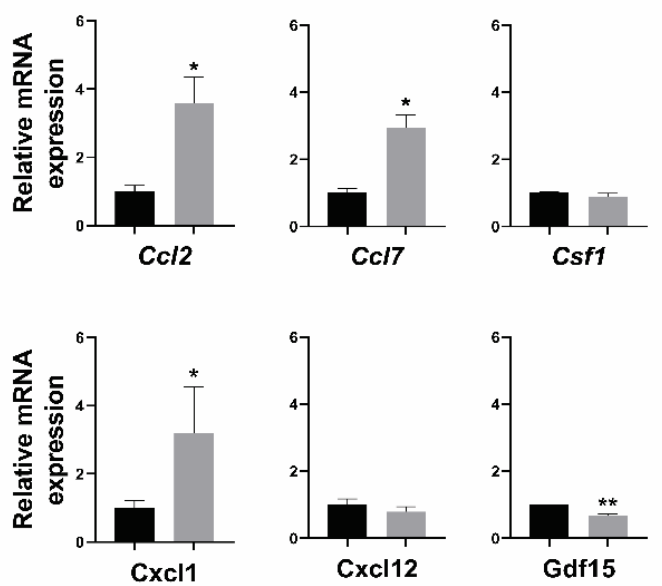
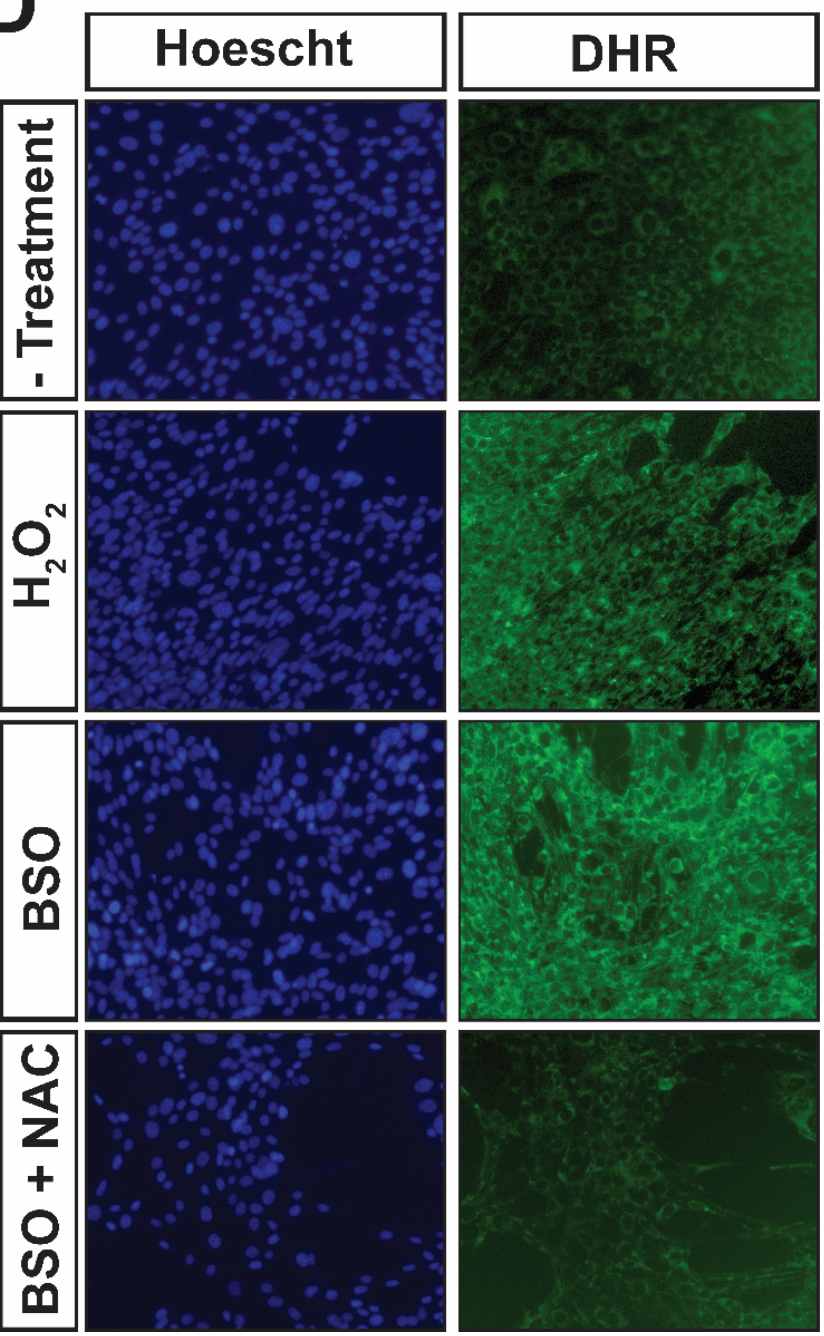


\section{Figure 6.}

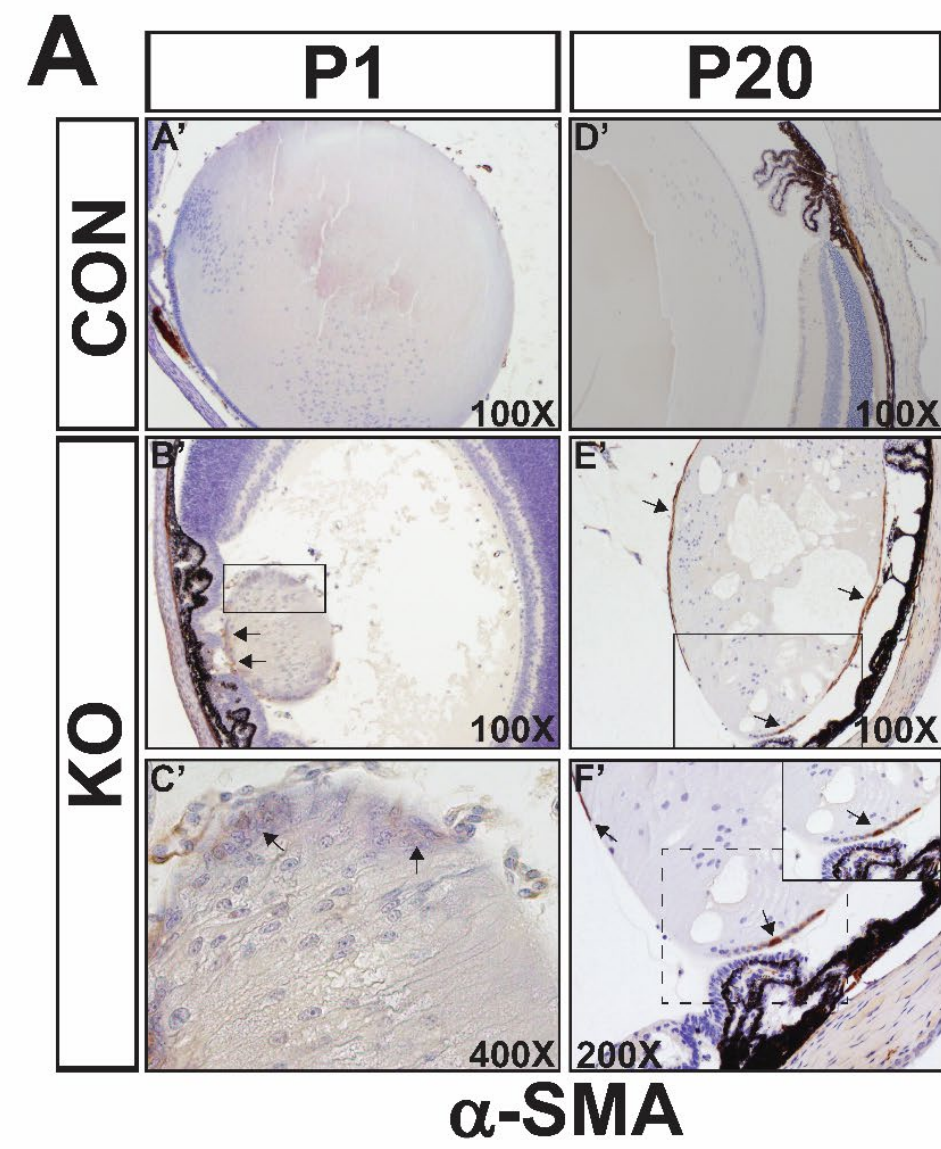

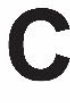

\section{Hoescht}

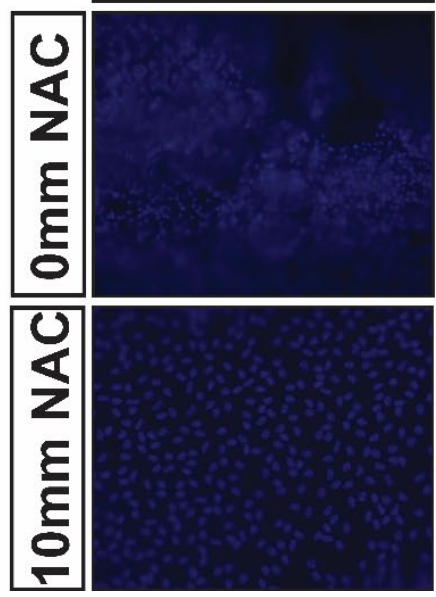

DHR

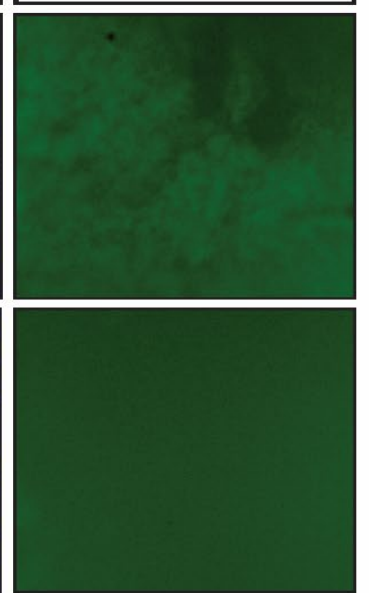

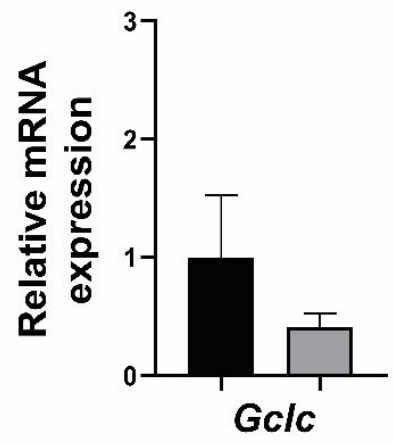
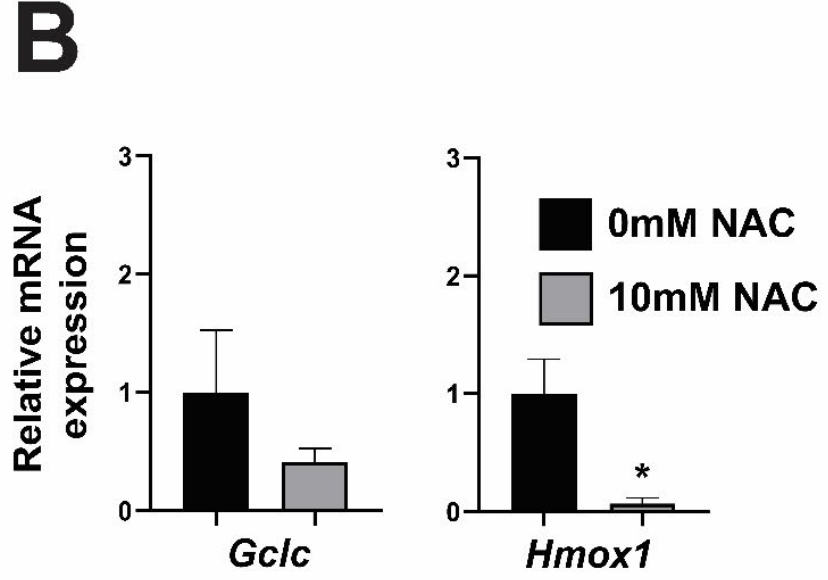

D
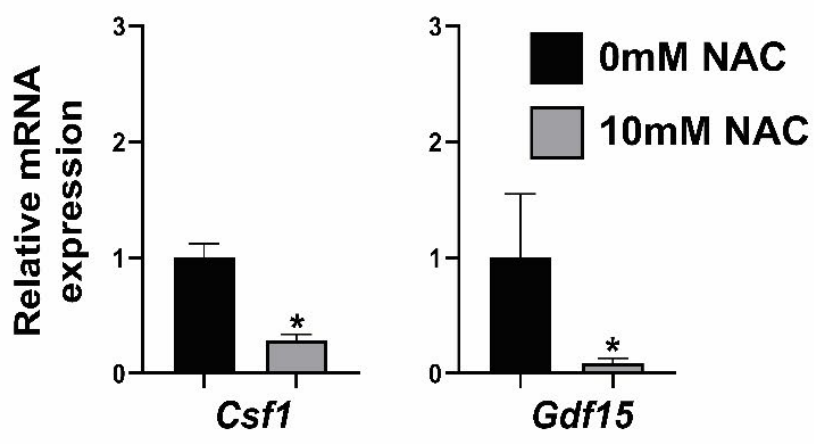
bioRxiv preprint doi: https://doi.org/10.1101/2021.10.16.464542; this version posted October 16, 2021. The copyright holder for this preprint (which was not certified by peer review) is the author/funder, who has granted bioRxiv a license to display the preprint in perpetuity. It is made available under aCC-BY 4.0 International license.

\section{$844 \quad$ Figure 7.}

845

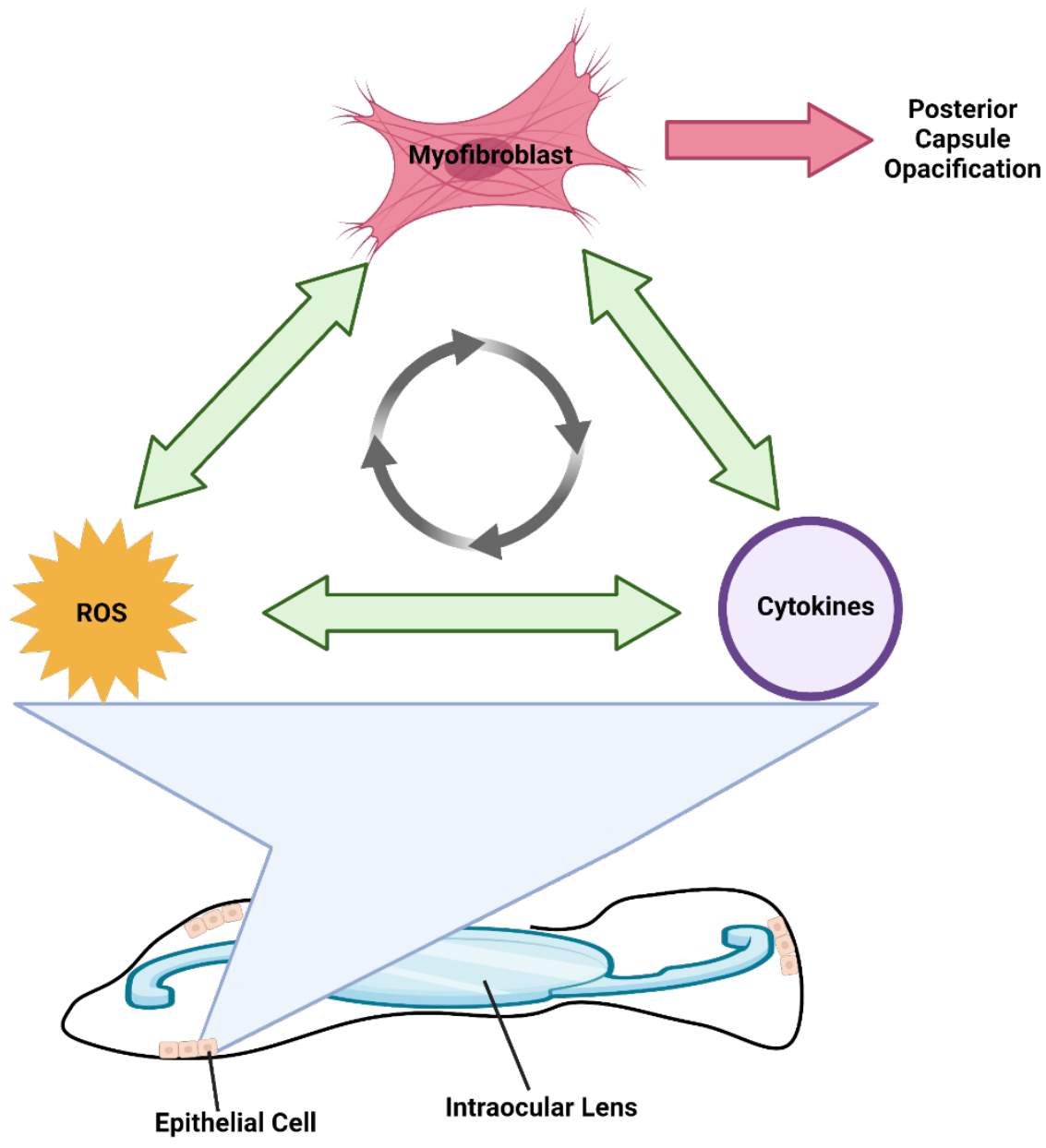


bioRxiv preprint doi: https://doi.org/10.1101/2021.10.16.464542; this version posted October 16, 2021. The copyright holder for this preprint

(which was not certified by peer review) is the author/funder, who has granted bioRxiv a license to display the preprint in perpetuity. It is made available under aCC-BY 4.0 International license.

\section{Supplemental Figure 1.}

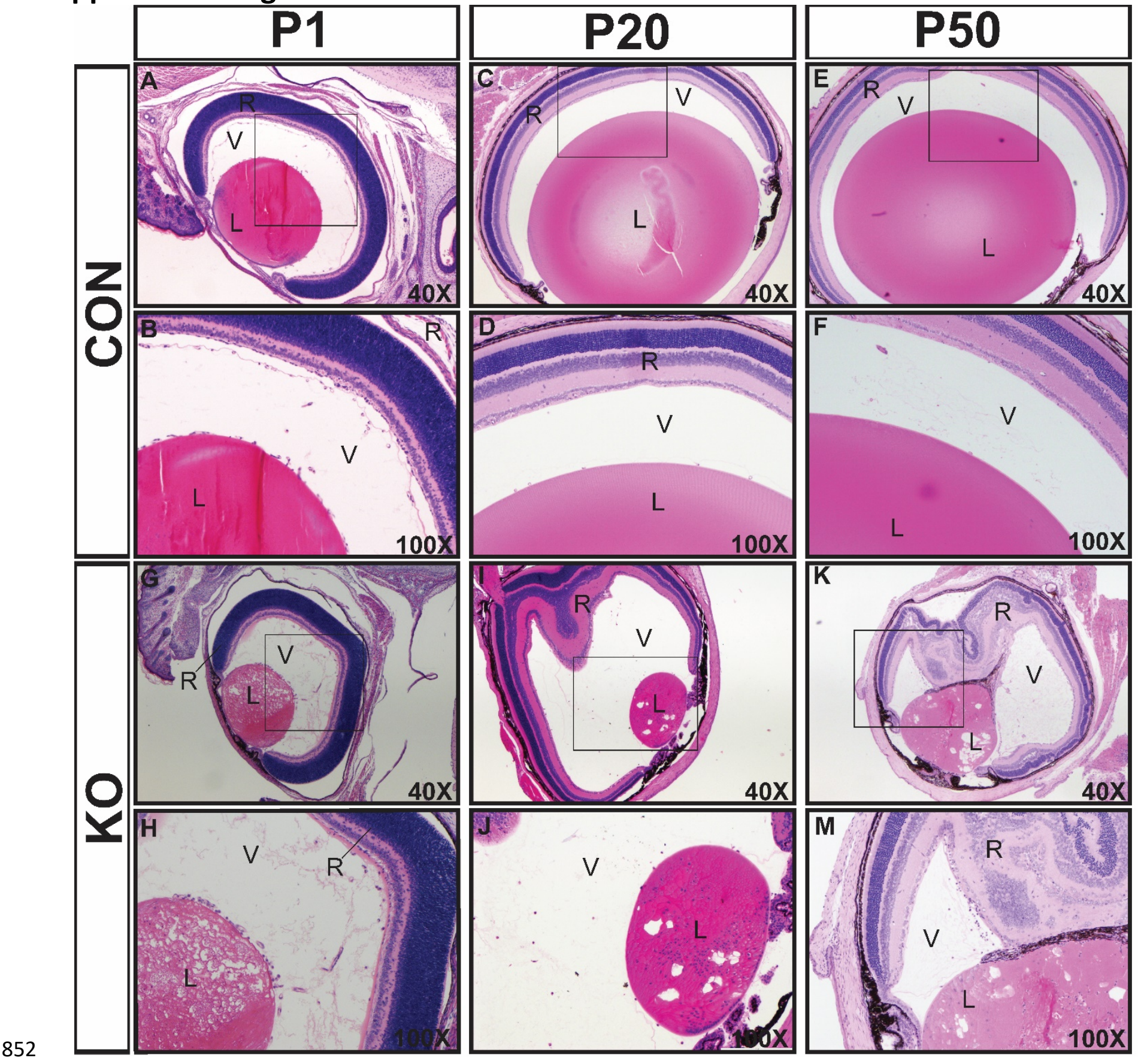




\section{9}

Supplemental Figure 2.

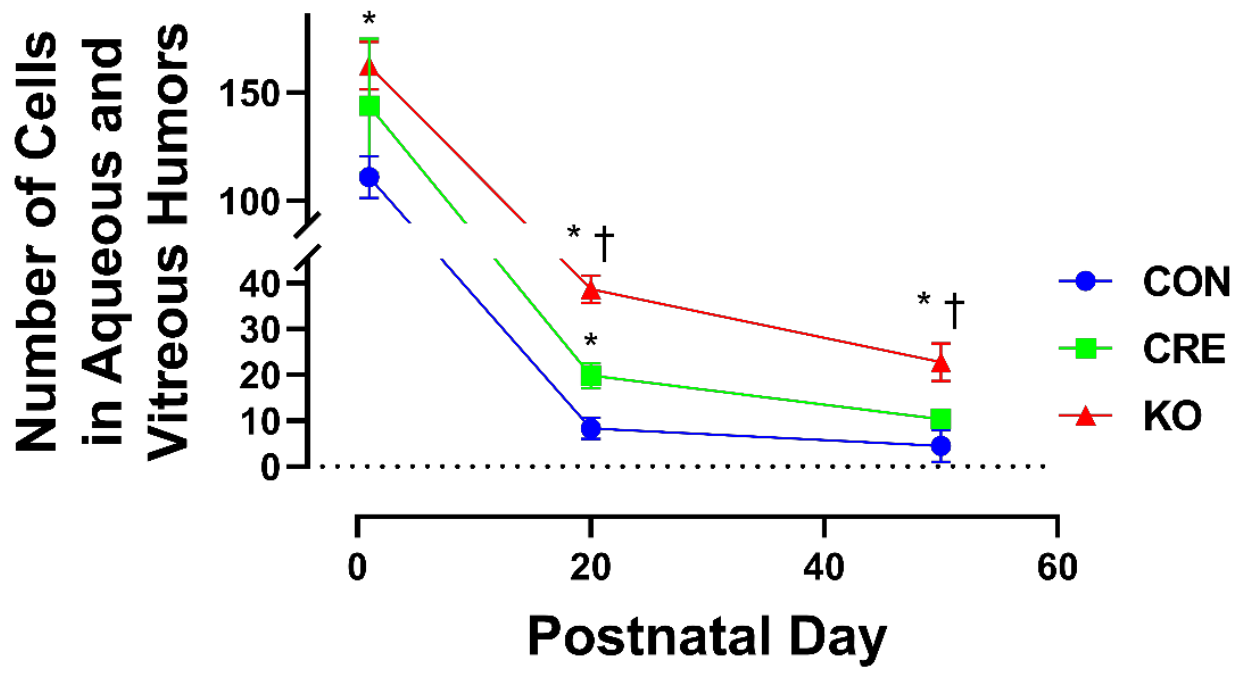


bioRxiv preprint doi: https://doi.org/10.1101/2021.10.16.464542; this version posted October 16, 2021. The copyright holder for this preprint

(which was not certified by peer review) is the author/funder, who has granted bioRxiv a license to display the preprint in perpetuity. It is made available under aCC-BY 4.0 International license.

\section{Supplemental Figure 3.}
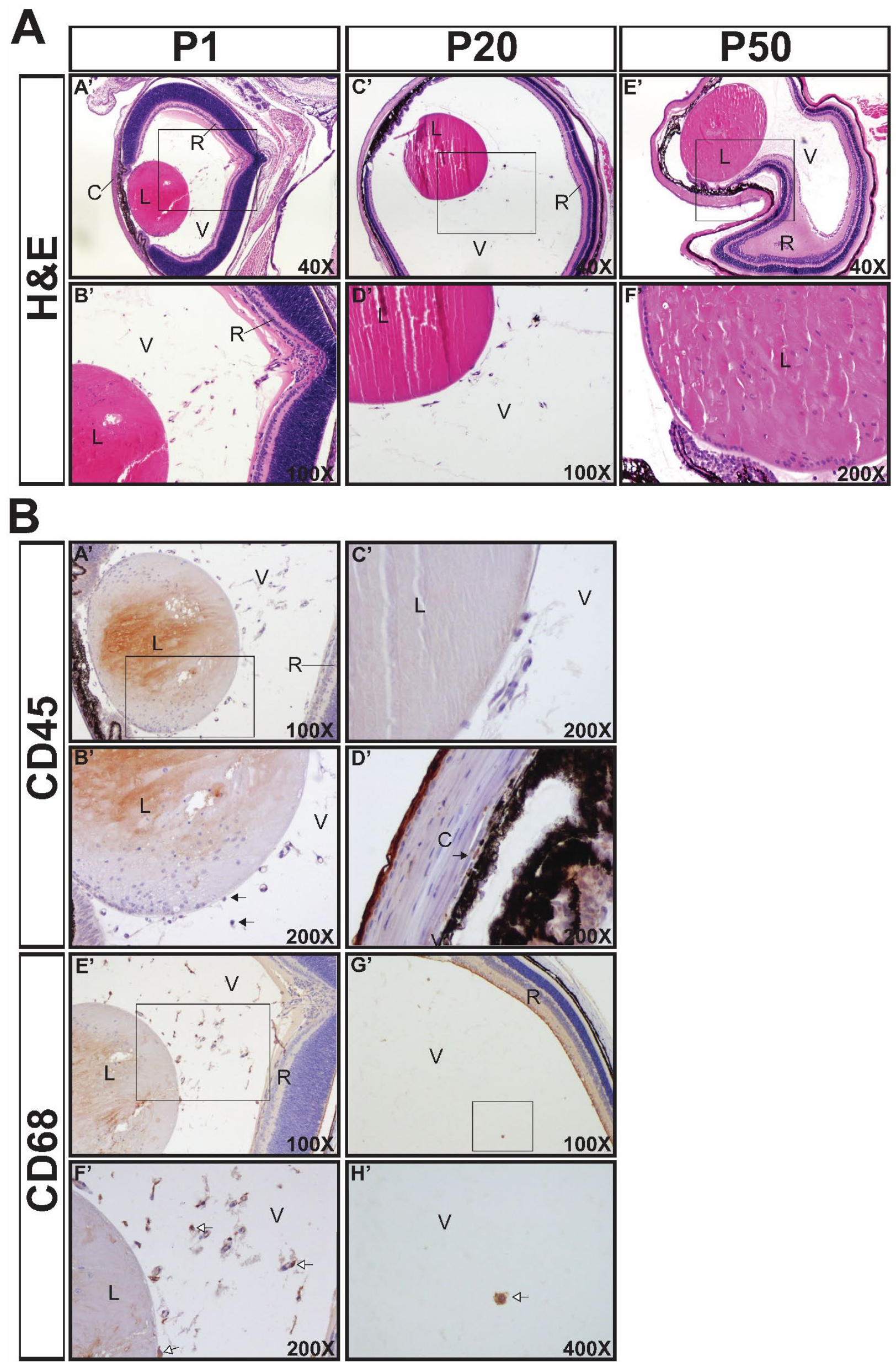


\section{${ }^{862}$ Supplemental Figure 4.}

\section{A}

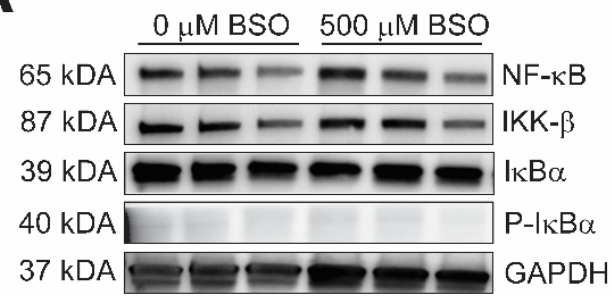

B
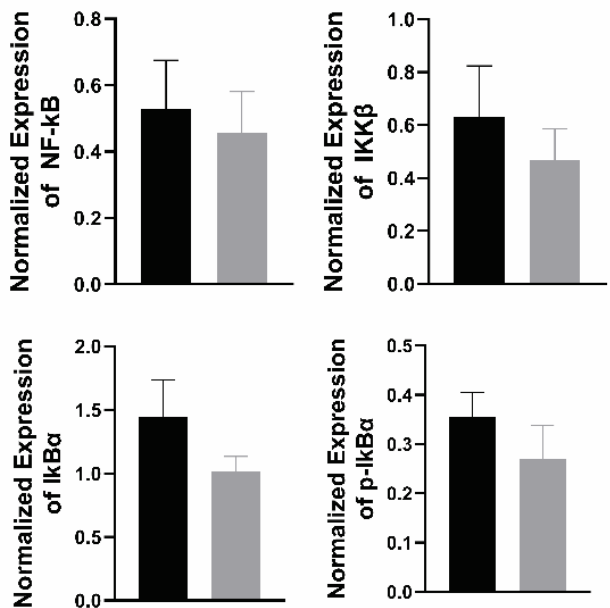

864

865

866

867

868

869

870

871

872

873
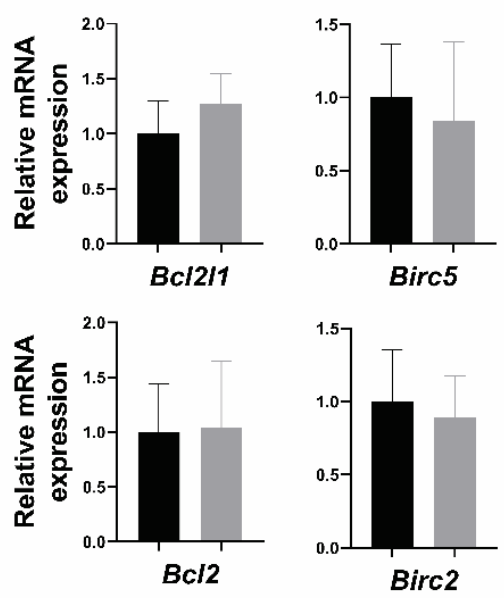

$0 \mu \mathrm{M}$ BSO

$500 \mu \mathrm{M}$ BSO

D

$0 \mu \mathrm{M}$ BSO

$500 \mu \mathrm{M}$ BSO
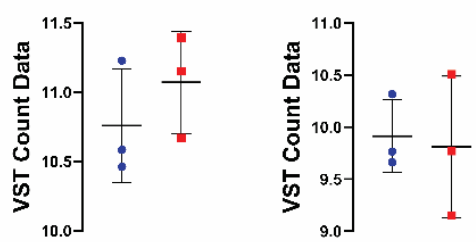

Bc/2

Birc2
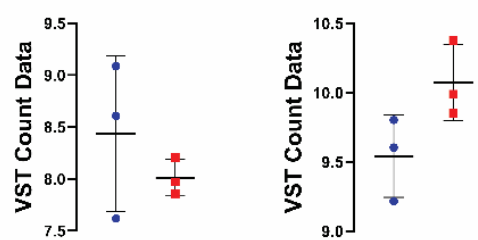

\section{4}


bioRxiv preprint doi: https://doi org/10.1101/2021.10.16.464542; this version posted October 16,2021 The copyright holder for this preprint (which was not certified by peer review) is the author/funder, who has granted bioRxiv a license to display the preprint in perpetuity. It is made available under aCC-BY 4.0 International license.

874

875

\section{Supplemental Figure 5.}

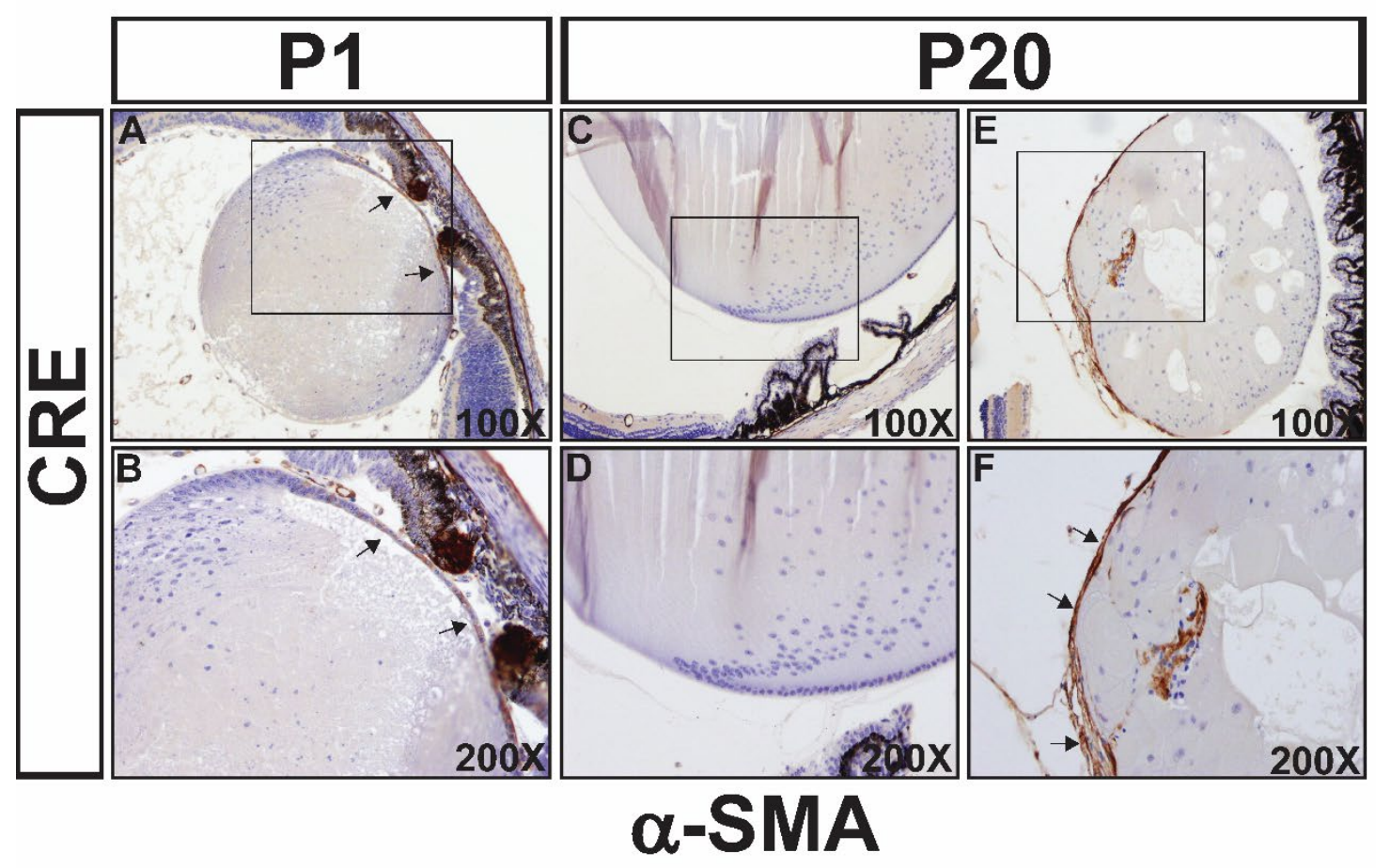

876

877

878

879

880

881

882

883

884

885

886

887 
890

\section{Supplemental Figure 6.}
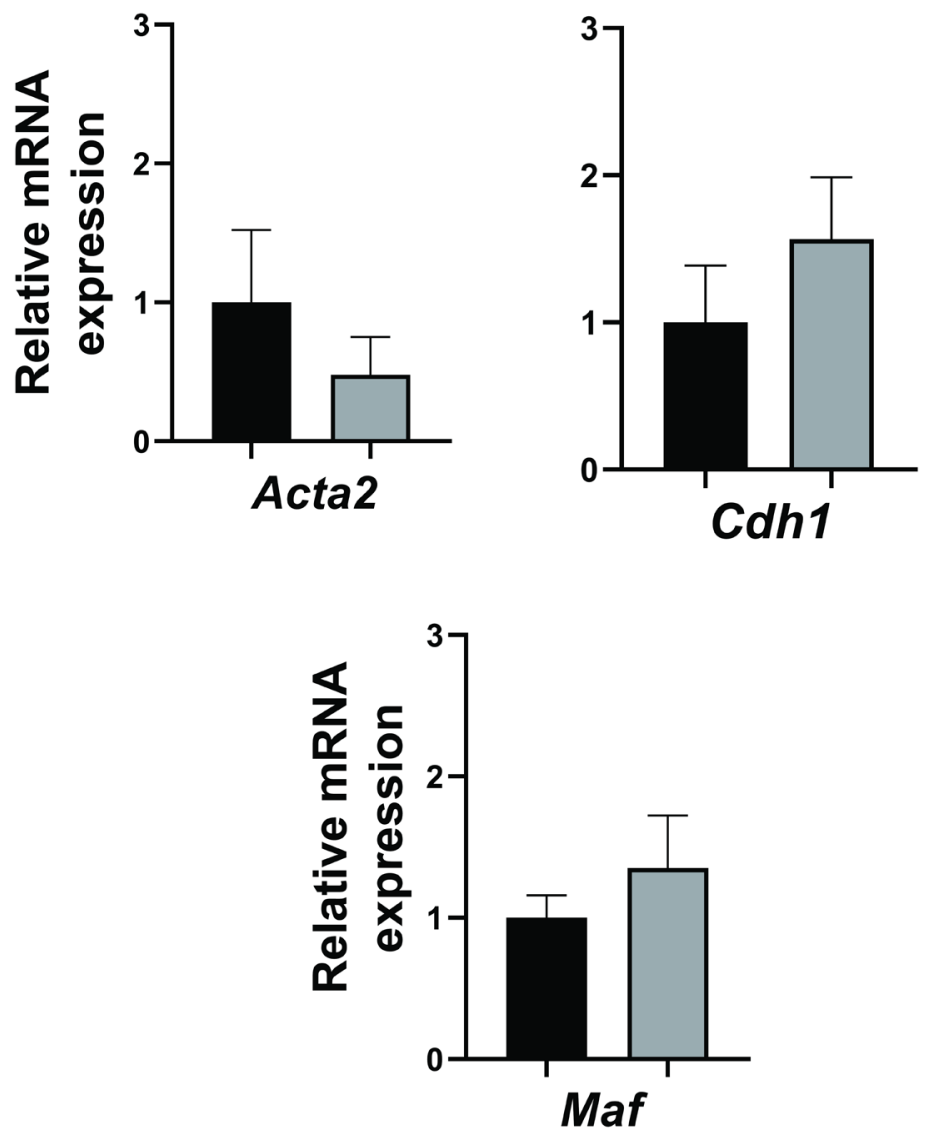

OmM NAC

891 
903

\section{Supplemental Figure 7.}
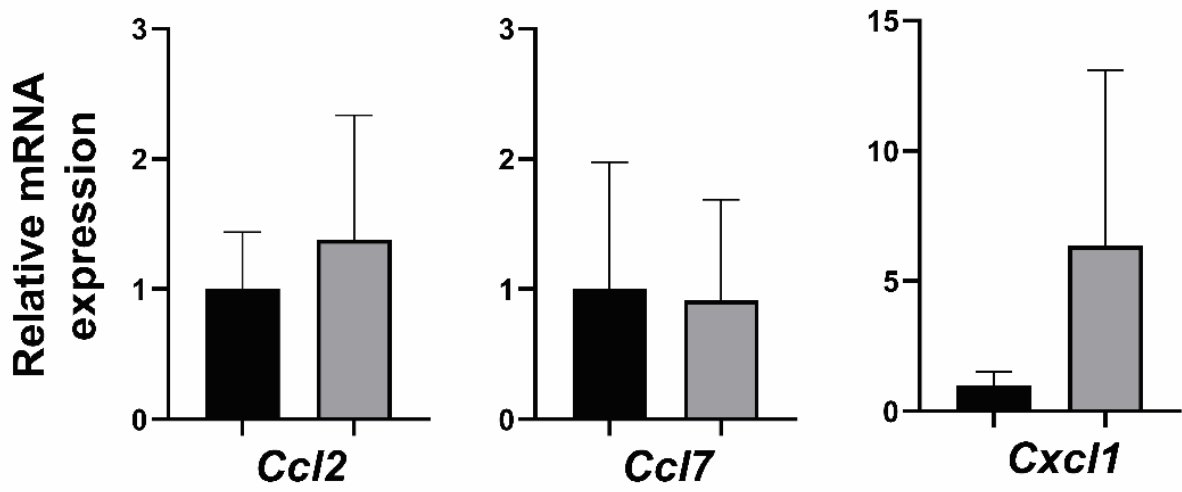

904

905

906

907

908

909 